\title{
Learning to Acquire
} How Serial Acquirers Build Organisational Knowledge for Information Systems Integration

Henningsson, Stefan

Document Version

Final published version

Published in:

European Journal of Information Systems

DOI:

10.1057/ejis.2014.18

Publication date:

2015

License

Unspecified

Citation for published version (APA):

Henningsson, S. (2015). Learning to Acquire: How Serial Acquirers Build Organisational Knowledge for Information Systems Integration. European Journal of Information Systems, 24(2), 121-144.

https://doi.org/10.1057/ejis.2014.18

Link to publication in CBS Research Portal

\section{General rights}

Copyright and moral rights for the publications made accessible in the public portal are retained by the authors and/or other copyright owners and it is a condition of accessing publications that users recognise and abide by the legal requirements associated with these rights.

\section{Take down policy}

If you believe that this document breaches copyright please contact us (research.lib@cbs.dk) providing details, and we will remove access to the work immediately and investigate your claim. 


\title{
Learning to acquire: How serial acquirers build organizational knowledge for information systems integration
}

\begin{abstract}
This paper develops a knowledge-based model of information systems (IS) integration in acquisitionbased growth programs. Previous research has found important differences in the acquirers' abilities for acquisition IS integration, and that these differences play key roles in explaining the economic benefits of acquisition-based growth. A knowledge-based view of acquisition IS integration contributes explanation to how differences in abilities arise. Our knowledge-based model is developed by an analytic induction approach, comprising both deductive and inductive analysis of the industry group Trelleborg. The analyses yield five propositions that explain the building of knowledge for acquisition IS integration by the mechanisms of routine refinement, superstitious learning, expertise building, sub-activity refinement and related expertise building. Together, the five propositions form a knowledge-based model of acquisition IS integration. The model suggests that 'serial acquirers' form the knowledge necessary for attending to an IS integration challenge over a series of heterogeneous acquisitions. Differences in acquirers' abilities for acquisition IS integration that depend on knowledge variations are therefore persistent and hard to overcome for the inexperienced acquirer.
\end{abstract}

Keywords: Acquisition, Merger, Serial acquirer, Information systems integration, IT integration, Knowledge-based view.

Running title: Learning to acquire 


\section{Introduction}

Appropriately executed, acquisitions of other companies and businesses can create business benefits of cost synergies, increased sales and future growth options (Haleblian et al., 2009; Hitt et al., 2009). To capture these benefits, many companies have made acquisition programs integrated parts of their corporate strategies (Barkema \& Schijven, 2008a; Parada et al., 2009; Keil et al., 2012). 'Serial acquirers' (Laamanen \& Keil, 2008), such as Siemens, Cisco, and Nestlé, frequently carry out several acquisitions every year. Historically, $60 \%$ of all acquisitions have been made by serial acquirers, defined here as acquirers who make at least two acquisitions every three years (Kengelbach et al., 2011).

Despite the potential benefits and popularity of acquisitions, value-creating acquisitions have proven to be difficult in practice (Haleblian et al., 2009). Acquisitions involve many challenges, including target selection, synergy estimation, contract negotiations, operational combination and information systems (IS) integration (see, for example, Haleblian et al., 2009; Keil et al., 2012). Compared to acquirers who make isolated deals, serial acquirers are even further exposed to acquisition challenges (Keil et al., 2012). These challenges include: deciding on pace and scope of the acquisition program (Hayward, 2002; Parada et al., 2009); estimating synergies between targets and past, current and future acquisitions (Voss, 2007); and managing several simultaneous integration projects (Barkema \& Schijven, 2008b). However, serial acquirers also have additional opportunities for realising value from their acquisitions. Serial acquirers can use their acquisition experiences to build knowledge for future acquisitions (Barkema \& Schijven, 2008a). A failed acquisition may create valuable learning effects that can enhance the performance of subsequent acquisitions more than its direct negative influence (Haleblian \& Finkelstein, 1999; Finkelstein \& Haleblian, 2002).

A number of studies point to the importance of gradually evolving organisational knowledge as one of the key factors affecting the value that serial acquirers extract from their acquisitions (e.g., Zollo \& Winter, 2002; Haleblian et al., 2006; Bingham et al., 2009). Intuitive logic says that acquirers will generally learn from their acquisition experiences and thereby improve the performance of acquisitions over time. However, when this logic was tested, studies found that while some acquirers do learn how to make acquisitions, others display no, or even negative, development of their abilities to create value through acquisitions (Haleblian et al., 2009).

A more refined view of how acquirers develop knowledge for acquisitions has emerged in recent years. In this 'knowledge-based view' of acquisitions (Zollo \& Singh, 2004; Bingham et al., 2009; Zollo, 2009), several different learning processes are at play. Each of these processes affects the organisational knowledge for making acquisitions through a different learning mechanism, and each of these 
mechanisms is dependent on the presence of specific contingencies (Barkema \& Schijven, 2008a). Consequently, acquisition experiences create different opportunities for learning how to do acquisitions. However, although the literature on formation of organisational knowledge for making acquisitions has matured significantly in the last decade, 'we've only scratched the surface in terms of understanding organisational learning' (Barkema \& Schijven, 2008a, p. 630).

In this paper, we further the knowledge-based view of acquisitions by investigating the mechanisms related to learning and improvements in organisational knowledge for one particular acquisition task: the integration of the acquirer's and the acquisition's information systems (IS) - henceforth referred to as acquisition IS integration. Between $45-60 \%$ of the expected business benefits from acquisitions are directly dependent on completed IS integration (Ketterer et al., 2009; Sarrazin \& West, 2011). Consequently, the combined organisation cannot function effectively until IS integration has been achieved (Evgeniou, 2002; Mehta \& Hirschheim, 2007; Henningsson \& Carlsson, 2011). In addition, previous research has shown that acquirers vary in their abilities to achieve acquisition IS integration (Stylianou et al., 1996; Robbins \& Stylianou, 1999; Tanriverdi \& Uysal, 2011). Together, this makes the acquirers' abilities for acquisition IS integration an important antecedent in explaining acquisition performance (Tanriverdi \& Uysal, 2011).

A knowledge-based view of acquisition IS integration complements the extant literature on acquisition IS integration by investigating how differences in abilities arise. Notwithstanding the valuable insights that prior research has provided on the importance of acquirers' abilities for IS integration, the literature contributes limited explanations to the origin of these differences. There is, however, initial evidence pointing in the direction that knowledge-building processes are also relevant for the specific task of acquisition IS integration. Examining Danisco, the Danish food ingredient company, Yetton et al. (2013) attribute Danisco's consistently effective acquisition IS integration partly to the organisational knowledge to design, plan and execute the IS integration project. Similarly, knowledge in the form of organisational routines (c.f. Nelson \& Winter, 1982; Levitt \& March, 1988) for acquisition IS integration has been brought forward as explanations for Cisco's successful expansion in networking services, CEMEX's equally successful growth from a Mexican cement producer to a global building materials supplier, and Banco Santander's efficient acquisition-based internationalisation strategy (Kanter et al., 2007; Parada et al., 2009; Brueller \& Capron, 2010).

By specifically investigating the building of knowledge for acquisition IS integration, we contribute to understanding of the more general question of how acquirers learn to make acquisitions in two ways. First, identifying and explaining learning processes related acquisition IS integration, we expand the scope of challenges that serial acquirers need to address. Second, theory building within the knowledge- 
based view of acquisition has primarily derived conclusions from studying operational integration of business processes (e.g., Zollo \& Singh, 2004; Bingham et al., 2009). The investigation of how abstractions from these studies apply specifically to IS integration introduces a new context of study, further insight into how learning mechanisms unfold and are influenced by contingencies (Haleblian \& Finkelstein, 1999; Zollo \& Singh, 2004).

Against this backdrop, the two-folded research question guiding this study is:

- What are the main learning mechanisms for organisations to build knowledge for acquisition IS integration, and how do these different learning mechanisms influence the building of organisational knowledge for acquisition IS integration?

We attend to this research question by an approach similar to analytic induction (Patton, 2002). An analytic induction approach starts deductively with the formulation of propositions, which are empirically validated by analysis of case data. The deductive analysis is followed by an inductive analysis in which the researcher re-analyses the empirical data to discover concepts and relationships not accounted for in the original propositions. In this study, we develop propositions by analysing the literature on acquisition IS integration from a knowledge-based view of acquisitions (Zollo \& Winter, 2002; Zollo \& Singh, 2004; Bingham et al., 2009). Through a case study of Trelleborg AB, the extent of empirical support for the propositions is examined. Then, following an inductive analysis, we re-analyse the case data to uncover additional insights from which we develop new propositions. In combination, the deductive and inductive analyses yield five propositions that together form a knowledge-based model of acquisition IS integration.

\section{Related literature and theory development}

By applying a knowledge-based view on acquisition integration, we contribute to the stream of research on acquisitions that draws on the resource-based view of strategy and its extension into organisational capabilities (see, for example, Barney, 1991; Peteraf, 1993). In this view, acquisitions create value by the sharing and transfer of complimentary resources and capabilities between the two organisations (Capron et al., 1998). Resources are tangible and intangible factors that a business owns or controls, including stocks of knowledge (Grant, 1996; Capron et al., 1998). An organisational capability is a specific type of resource, representing the ability to perform an action using the available resources (Grant, 1996).

We begin this section by reviewing the extant literature on acquisition IS integration. The review makes up the basis for analysing acquisition IS integration from a knowledge-based view. 


\section{Acquisition IS integration}

Figure 1 outlines a generic view of the acquisition process and the emerging understanding of IS integration challenges in this process. The broad conclusion is that the principal contribution of IS integration in acquisitions lies in the realisation of contingent business benefits (Johnston \& Yetton, 1996; Giacomazzi et al., 1997; Wijnhoven et al., 2006; Mehta \& Hirschheim, 2007). To this end, the IS function needs to engage in the different phases of the acquisition process.

\section{[Figure 1]}

IS integration analysis refers to the assessment of the acquisition's starting conditions and the desired tobe scenario (Merali \& McKiernan, 1993; Böhm et al., 2011). Subsequently, the issues of how to shape the IS integration project are addressed in IS integration planning (Mehta \& Hirschheim, 2007; Alaranta \& Henningsson, 2008). This includes securing access to critical IT systems, data to be transferred and competences to carrying out the following implementation. When the acquirer obtains control of the new business, the mostly technical work of the IS integration implementation takes place (Stylianou et al., 1996; Wijnhoven et al., 2006).

Some of the experienced problems of acquisition IS integration have been attributed to the absence of IS integration analysis and planning before signing the acquisition deal (Alaranta \& Henningsson, 2008). As the business benefits are contingent on completed IS integration, IS functions are often expected to integrate IS as quickly as possible with minimal disruptions to the business (McKiernan \& Merali, 1995; Wijnhoven et al., 2006). The pressure is exacerbated by external stress from shareholders and other stakeholders to realise promised synergistic effects (Johnston \& Yetton, 1996; Mehta \& Hirschheim, 2007).

Alaranta and Henningsson (2008) contend that the planning of the IS integration strategy should follow a thorough analysis of the synergistic effects expected from the acquisition. The analysis frames the IS integration project, suggesting a path to acquisition IS integration with specific decisions needing to be made based on the initial conditions. Along similar lines, IS integration strategy and acquisition benefits have been described as an alignment process (Johnston \& Yetton, 1996; Giacomazzi et al., 1997; Wijnhoven et al., 2006; Mehta \& Hirschheim, 2007).

Henningsson and Yetton (2013) identifies three generic strategies to acquisition IS integration, and explains how they combine the acquirer's and target's IS resources by different integration mechanisms. These mechanism enables different business benefits, and are thus appropriate in different situations:

- In IS absorption, the target's IS are replaced by the acquirer's existing IS. Data from the target's IS are migrated to the acquirer's IS. An IS absorption strategy is suitable when the target's business can 
be supported by the functionality of the acquirer's IS (Johnston \& Yetton, 1996; Giacomazzi et al., 1997; Wijnhoven et al., 2006).

- In IS co-existence, some of the target's IS are kept after the acquisition. In full co-existence, all of the target's IS are retained and bolted on to the acquirer's IS. In partial co-existence, some of the target's IS are replaced by IS from the acquirer. Bridges are created between the acquirer's IS and IS retained from the target. The co-existence strategy suits acquisitions were the target cannot be supported by the acquirers IS, and when the degree of IS integration needed is limited (Johnston \& Yetton, 1996).

- In IS renewal, new IS are developed to support the combined unit. This is frequently costly and practically difficult, but necessary when neither the acquirer's nor the target's IS support the business of the combined unit (Wijnhoven et al., 2006; Mehta \& Hirschheim, 2007).

Figure 2 schematically presents the three acquisition IS integration strategies. The different IS integration strategies and their conditions for application summarise the nature of the acquisition IS integration challenge.

[Figure 2]

\section{A knowledge-based view of acquisition IS integration}

The knowledge-based view of organisations, as an extension of the resource-based view of organisations (e.g., Barney, 1991; Peteraf, 1993), was originally motivated by the argument that knowledge is the most important resource in creating sustained competitive advantage (Kogut \& Zander, 1992; Grant, 1996; Spender, 1996). Intangible company-specific knowledge resources enable value addition to incoming factors, while all tangible resources can be acquired from the relevant factor market (Grant, 1996; Spender, 1996). When combined with the area of strategic management, the knowledge-based perspective reframed the resource-based analysis of strategy from what arrangements of resources create economic rents, to how organisations learn and improve knowledge resources over time (Grant 1996; Spender 1996).

The knowledge-based perspective identifies two fundamentally different types of organisational knowledge: organisational routines and organisational expertise. An organisational routine is 'a coordinated, repetitive set of organisational activities' (Miner, 1991, p. 773). This focus on repeated activities is a common feature in much of the literature on organisational routines (e.g., Nelson \& Winter, 1982; Levitt \& March, 1988). A routine is done without too much conscious thinking (i.e., 'routinized') (Nelson \& Winter, 1982). Knowledge, in the form of tacit "know-how" for how to complete the task that 
a routine addresses, is built into the routine itself (Polanyi, 1966; Nonaka, 1994). We refer to this tacit know-how built into the refined routine as routine-based knowledge.

Organisational expertise refers to organisations' emergent frameworks for interpreting and deliberately acting upon experiences (Levitt and March, 1988). Organisations with expertise in an area describe and explain the complex problems in that area with higher granularity and more refined categorisations than do organisations without expertise in the area (Day \& Lord, 1992). This enables them to cope with ambiguities in complex tasks, such as acquisitions (Levitt and March, 1988). Following Levitt and March (1998), we define organisational expertise as a conceptual framework for interpreting and acting upon experiences.

Within the acquisition literature, research building on the knowledge-based view has investigated the processes by which acquirers develop organisational knowledge for making acquisitions (Barkema \& Schijven, 2008a). Conditioned by the presence of specific contingencies (for example, frequency and heterogeneity of acquisition experiences), serial acquirers can develop both acquisition routines, allowing them to efficiently integrate specific types of acquisitions (e.g., Fowler \& Schmidt, 1989; Barkema et al., 1996; Haleblian \& Finkelstein, 1999) and acquisition expertise, allowing them to interpret and act upon acquisition experiences (Bingham et al., 2009).

Here, we develop propositions for how what is known about knowledge building for acquisition integration in general transfers to the specific case of knowledge building for acquisition IS integration. This includes how known learning mechanisms and their respective contingencies translate to acquisition IS integration.

Drawing on the knowledge-based perspective of acquisitions, our analysis focuses on two types of organisational knowledge relevant for acquisition IS integration: acquisition IS integration routines and acquisition IS integration expertise. The former are coordinated, repetitive sets of organisational activities for implementing the different IS integration strategies (c.f. Nelson \& Winter, 1982; Miner, 1991). The latter refers to a conceptual framework for interpreting acquisition IS integration experiences (c.f. Levitt \& March, 1988).

These two knowledge types are developed through mechanisms of routine refinement, superstitious learning and expertise building from previous acquisitions experiences. Routine refinement refers to the 'semi-automatic' (learning by doing) refinement of organisational routines while repeating similar tasks over and over again (Cohen et al., 1996). Superstitious learning refers to the process of incorrectly interpreting cause and effect of actions, leading to erroneous assumptions about how to deal with a subsequent challenge (Levitt \& March, 1988; Zollo, 2009). The process of expertise building resembles 
retrospective sensemaking (Weick, 1995), in which the acquiring organisation, through reflection and evaluation (deliberate learning mechanisms), builds its conceptual framework for managing acquisitions (Zollo \& Singh, 2004).

The relationships between knowledge types and learning mechanisms are displayed as three propositions in Figure 3. In the following, the three propositions are explained and justified.

\section{[Figure 3]}

\section{Routine refinement}

A large body of literature has used research on learning curves, originally developed to understand how organisations learn to master manufacturing processes, to test if learning processes exist within serial acquirers (e.g., Fowler \& Schmidt, 1989; Barkema et al., 1996; Haleblian \& Finkelstein, 1999). The original research on learning curves established that organisations, while repeating the same task over again, refined how the task was carried out and established an efficient routine for the task (see Yelle, 1979). This routine refinement is described as 'semi-automatic' (Zollo \& Singh, 2004) by the matching of procedures to situations (Cyert \& James, 1963). Linking experience directly to performance also predicted improvements in other operational tasks, such as pricing and distribution (Zollo \& Singh, 2004; Barkema \& Schijven, 2008a).

For acquisitions, some scholars have found a positive relationship between experience and financial performance measurements, while others have found non-significant, negative, or U-shaped relationships (see Barkema \& Schijven, 2008a; Haleblian et al., 2009). The differences in results have been attributed to various contingencies, including different types of acquisitions that are unequally represented in the investigated samples (Zollo \& Singh, 2004; Barkema \& Schijven, 2008a). The limited correlation between previous experience and acquirer performance has been explained by the fact that 'acquisitions are far more complex than activities at the operating level, such as manufacturing, pricing, and distribution' (Barkema \& Schijven, 2008a, p. 595). While operational tasks are fairly repetitive, strategic tasks, such as acquisitions, present a high degree of heterogeneity. It is therefore not possible to establish one organisational routine that matches all types of acquisitions (Haleblian \& Finkelstein, 1999).

The broad conclusion from research on acquisition routines is that experience generally leads to improvement by routine refinement if the subsequent acquisition corresponds to previous experiences (Cohen \& Levinthal., 1990; Barkema et al., 1996). If the organisation undertakes a set of similar acquisitions, it can establish an efficient routine for the challenges of that acquisition type by evolutionary refinement in the same way that organisations learn to master manufacturing processes (Zollo \& Singh, 2004; Barkema \& Schijven, 2008a). 
The three strategies for acquisition IS integration present different possibilities for establishing routinebased knowledge. Experience homogeneity is the key word for IS integration routine refinement (c.f. Cohen \& Levinthal, 1990; Barkema et al., 1996). If tasks are similar enough, the acquirer can refine its IS integration routine, making integration more efficient (Barkema \& Schijven, 2008a). On a high level, all IS integration projects go through analysis, planning and implementation. However, the three strategies differ fundamentally in their sets of activities (Johnston \& Yetton, 1996).

In concrete terms, IS absorption includes the transfer of customer and operational data from the target's IS to the IS of the acquirer. The acquirer's IS are then expanded to embrace the new physical locations, for example, production facilities or sales offices that are the result of absorbing the target's operations (Giacomazzi et al., 1997; Wijnhoven et al., 2006; Tanriverdi \& Uysal, 2011). IS absorption means "deepening" the use of existing IS. Karim and Mitchell (2000) describe resource deepening as a relatively simple process that normally follows the same basic structure.

Now, consider IS absorption as resource deepening being a relatively homogenous process that can be evolutionarily refined into an efficient routine. This would explain how companies such as CEMEX can display a repeatedly successful (with respect to low cost and high speed) IS integration routine (Robertson et al., 2007). As part of its internationalization strategy CEMEX has repeatedly acquired local cement producers, which has been integrated by an IS absorption strategy. In doing so, CEMEX introduces bestpractices and efficient routines carried by their centralised IS structure (Kanter et al., 2007). Similarly, Banco Santander built superior IT-based capabilities in its home base that through an internationalization process were implemented in acquired businesses (Parada et al., 2009). In each acquisition, Santander used an IS integration strategy similar to IS absorption, that the bank mastered to excellence (Parada et al., 2009). Given the tasks required for IS absorption, it makes sense that repeated acquisition with IS absorption would, from an IS integration perspective, imply doing "more of the same," thus leading to an evolutionary refinement of the IS absorption routine.

IS co-existence and IS renewal involve extending functionality of the acquirer's IS (c.f. resource extension, Karim and Mitchell, 2000). These resource elaborations are more heterogeneous experiences, as they imply explorative change (Karim and Mitchell, 2000). In IS co-existence and IS renewal, each activity is associated with different options of how to carry out the activity, for example, architecture and intensity for the bridges between systems in IS co-existence (c.f. Massetti \& Zmud, 1996; Markus, 2000; Al Mosawi et al., 2006). Repeated IS co-existence and/or IS renewal projects would provide limited possibilities for routine refinement. It is therefore not likely that acquirers could establish organisational routines for IS co-existence or IS renewal projects. Accepting this difference in the probability of 
different types of IS integration strategies to generate a homogenous set of IS integration experience, we propose:

P1. Repeated acquisition IS integration addressing a homogenous set of IS integration challenges enables routine refinement and the establishment of an efficient IS integration routine for the specific IS integration challenge.

\section{Superstitious learning}

The negative and U-shaped relationship between acquisition experience and performance has been explained by that acquirers, at least initially, draw the wrong conclusions from their acquisition experiences (Haleblian \& Finkelstein, 1999; Barkema \& Schijven, 2008a). Acquisitions are prone to outcome and causal ambiguity: it is hard to understand the outcome of an integration project beyond measurements of time and budget, and it is difficult to understand what has led to the ambiguous outcome (Levitt \& March, 1988; Zollo, 2009).

We define superstitious learning as failure to understand the "true" causes of a specific outcome making acquirers incorrectly think that they know what needs to be done, i.e., acquirers make erroneous categorization of experiences (Levitt \& March, 1988). Supporting this explanation, Zollo (2009) has found that managers' perception of success in previous acquisitions is negatively related to performance in the subsequent acquisition. Similarly, in the decision science literature, causal and outcome ambiguities have been related to decision makers' overrating their own performance (Levitt \& March, 1988).

The combined effect of erroneous categorization and overrating of own performance has been demonstrated by Cohen and Bacdayan (1994). They report that individuals who accumulate experience in a card game with a specific set of rules have an initial disadvantage over novice players when the rules of the game slightly change. This negative effect has been found in organisational decision making in general (e.g., Gavetti et al., 2005) and for acquisition-related decisions by Zollo and colleagues (Zollo, 2009; Zollo \& Reuer, 2010; Zollo \& Singh, 2004). The consequence is that the performance, generally, is lower for acquirers with few acquisition experiences compared with acquirers without acquisition integration experience. The former may try to map existing routines onto situations that do not fit the context. The latter build the acquisition IS integration process from scratch (Haleblian \& Finkelstein, 1999; Zollo \& Singh, 2004; Barkema \& Schijven, 2008a; Zollo, 2009).

Now consider how organisations apply the routines they develop. An organisation does so by 'matching procedures to situations more than it does calculating choices' (Levitt \& March, 1988, p. 320). As argued by Simon (1955), organisations are directed towards targets. Their behaviour depends on the targets they are striving for and their previous experiences of achieving these targets. 
Then consider acquisition IS integration. Outcome ambiguity is a general problem for IT-based capabilities when considering organisational performance as the ultimate objective of IT investments. In contrast to resources such as brand equity or production where improvements have a direct impact on performance measures, IT-based resources contribute to organisational performance through complex impact chains (Clemons \& Row, 1991; Wade \& Hulland, 2004).

Consequently, IT-based resources are prone to superstitious learning (Barley, 1988). This may lead to problems in acquisition IS integration, because acquirers tend to overrate the efficiency (Zollo, 2009) and misunderstand the applicability (Zollo \& Singh, 2004) of integration routines. The acquirer incorrectly categorizes (regarding efficiency and applicability) its acquisition IS integration experiences. This increases the risk of selecting and applying a suitable acquisition IS integration strategy. Formally, we propose:

P2. Through superstitious learning, acquirers with a homogenous set of acquisition IS integration experiences risk incorrectly categorizing their IS integration experiences.

\section{Expertise building}

An alternative to the direct experience accumulation is the deliberate learning process related to articulation and codification of previous experiences (Zollo \& Singh, 2004). How organisational knowledge and practices evolve and transfer across organisations is related not only to the degree to which knowledge is possible to be articulated and coded, but also to the degree to which organisations choose to engage in articulation and coding (Zollo \& Singh, 2004). These activities increase the probability of understanding the true causes for outcomes in the highly complex acquisition act (Zollo \& Singh, 2004).

The effects on learning of deliberate mechanisms are more effective when frequency is low rather than high, and tasks are homogeneous rather than heterogeneous (Zollo \& Winter, 2002). Deliberate learning counters the effects of drawing wrong conclusions from superstitious learning. It develops heuristic knowledge that extends beyond the particular acquisition at hand. This is supported by Bingham et al.'s (2009) qualitative study of how acquirers build acquisition capabilities over time. Expanding internationally, the six companies in the study make disparate acquisitions to enter new markets. In doing so, they are building expertise rather than refining acquisition routines.

Bingham et al. (2009) expand the concept of expertise with respect to acquisition integration. Illustrated with an analogy of how skilled chess players master the game of chess, they describe expertise as a "heuristic portfolio." The heuristic portfolio essentially corresponds to the conceptual framework described by Levitt and March (1988). However, in addition to the ability to categorise experiences with 
higher granularity, Bingham et al. (2009) expand the abilities associated with the framework to include the category of contextualisation, referring to abilities related to application of general tools and processes in the specific organisational context of an acquisition.

Regarding the process of building expertise, Bingham et al. (2009) and Zollo and Singh (2004) highlight that what seems of importance for expertise building is not primarily the final artefacts produced (evaluation reports, manuals, checklists, IT support, etc.) in the deliberate learning processes, but the understanding emerging from the process of producing them. Drawing on retrospective sensemaking (Weick, 1995), Zollo and Singh (2004) see expertise building as a process in which the acquiring organisation, through reflection and evaluation (deliberate learning mechanisms), builds its conceptual framework for managing acquisitions (Zollo \& Singh, 2004). Importantly, to develop these conceptual frameworks, experiences cannot be too similar. If so, they do not contribute to expanding the cognitive ability of experience categorisation (Hayward, 2002).

Adopting the conceptual framework and the heuristic portfolio described above, we both theoretically and empirically derive the specific abilities that can be associated with acquisition IS integration expertise. To extend the acquisition IS integration capability beyond efficient IS integration routines, acquirers must build heuristic knowledge related to categorisation and contextualisation of acquisition experiences (c.f. Bingham et al., 2009). This expertise is built by evaluating and reflecting on acquisition IS integration experiences. To build acquisition IS integration expertise, experiences cannot be too similar, as this leads to an efficient routine rather than expertise knowledge (c.f. Hayward, 2002).

As mentioned, the IS absorption, representing resource deepening, is a relatively homogenous experience from one integration to another (Karim \& Mitchell, 2000). Conversely, resource extensions are frequently heterogeneous experiences. In the IS co-existence approach, potential acquisition benefits should be matched to a multitude of IS integration options. The IS co-existence approach thus represents a multitude of IS integration paths. Similarly, the IS renewal process, which implies the development of new IS, is an explorative process (c.f. March, 1991) that, per definition (development of new IS), never happens twice, and thus cannot be routinized (Wijnhoven et al., 2006).

The knowledge necessary for understanding whether a routine with proven efficiency in the past is also appropriate for a subsequent acquisition corresponds to the contextualisation abilities described by Bingham et al. (2009). For example, assessing whether a routine for IS integration of an additional production facility by peer-to-peer architecture to realise coordination and scheduling economies can also be used for extending the acquirer's IS vertically by service-oriented architecture to integrate one of the company's distributors is not a routine-based decision. We contend that the reasoning on acquisition expertise is applicable also to acquisition IS integration. Therefore: 
P3a. Over time, contingent on variance in IS integration experiences and presence of deliberate learning mechanisms, acquirers can develop conceptual frameworks that allow them to categorise acquisition IS integration experiences.

P3b. Over time, contingent on variance in IS integration experiences and presence of deliberate learning mechanisms, acquirers can develop conceptual frameworks that allow them to contextualise acquisition IS integration experiences.

\section{Methodology}

The research presented in this paper followed an approach similar to analytic induction (Patton, 2002), with the purpose of developing an explanatory theory (See, for example, Gregor, 2006) on how organisations build knowledge for acquisition IS integration. The intent was to develop a mid-range theory rather than an abstract, grand theory (c.f. Lee, 2010).

\section{Case study design and data collection}

Our analytic induction approach was based on a positivist case study (Dubé \& Paré, 2003). The positivist approach in which we examine a set of predefined propositions (Dube \& Pare, 2003; Yin, 1984), is different from critical or interpretive case study research, where the objective is social critique or understanding the social construction of reality (Klein \& Myers, 1999). Although we accept that knowledge can ultimately be seen as socially constructed, this study frames learning mechanisms and knowledge as progression in abilities from a simplified, modest foundationalist (Feldman, 2003) view of unmediated experiences of a real world.

In modest foundationalism, assumptions are made about the existence of certain key elements that allows for theory building until reasons to challenge these assumptions are found. For this study, we are thus assuming that the learning processes in question do exist and that their influence on IS integration abilities can be captured by regarding them as real world objects. Taking this position, we adhere to a stream of organisational learning research that seeks to balance the study of behavioural mechanisms and cognitive processes (e.g. Glynn et al., 1994; Zollo \& Winter, 2002; Bingham et al., 2009).

The case setting supports the examination of how theoretical constructs translate into a new application area (George \& Bennett, 2004), and is particularly useful for understanding development processes (Van de Ven, 1992). The case setting is also suitable for rich exploration of acquisition IS integration (Henningsson et al., 2010; Carlsson et al., 2011). The prospect of a study based on rich process data to uncover additional insights about the mechanisms behind knowledge-building for acquisitions is noted in previous research on the subject matter (See Haleblian \& Finkelstein, 1999, and Bingham et al., 2009). 
Access to the case company, Trelleborg, was achieved through Trelleborg's long-term "learning partnership" with the first author's academic institution. In the partnership, Trelleborg financed research on significance to the organisation, including the study in this paper. Trelleborg was an appropriate setting for studying knowledge building and acquisition IS integration for two reasons. First, multiple acquisition experiences are necessary to build expertise knowledge for acquisition integration ( Zollo \& Singh, 2004; Barkema \& Schijven, 2008a; Zollo, 2009). Between 1996 and 2009 (when data collection for this article ended), Trelleborg AB made 69 acquisitions (Appendix A). Second, Trelleborg was reputed to be a skilled acquirer that frequently was able to efficiently realize potential acquisition benefits. This gave prospects for concretising expertise for acquisition IS integration.

Covering all of Trelleborg's acquisitions was deemed to be practically unattainable. Instead, we decided to focus on a subset representing key characteristics of the learning mechanisms and theoretically derived propositions. Trelleborg's knowledge building is treated here as the overall case study, and the subset of acquisitions as sub-cases that: a) allowed for snap-shots of the existing IS integration knowledge at the time, and b) became focal points in the investigation of the origin of knowledge. The first case was selected because, according to Trelleborg, it gave a comprehensive picture of the IS-related acquisition challenges. A retrospective case-study gives the possibility to rapidly assess the theoretical framework's general ability to capture important aspects of the case (Van de Ven, 1992). However, as retrospective stories frequently are biased, they have to be complemented with real-time case studies at a later stage (Van de Ven, 1992).

The first case gave a rich picture of what the organisation was able, and not able, to do in the years after 1996. Subsequent cases were theoretically sampled along the course of research (c.f. Eisenhardt, 1989) to enable the study of how the organisation evolved with respect to IS integration of acquisitions. Together, the four cases represent: a) both acquisition IS integration after few and many acquisition experiences, b) homogeneity and heterogeneity in IS integration challenges and c) presence and absence of deliberate learning mechanisms.

Table 1 describes the selection criteria and data collected to capture IS integration. Interviews were the primary method of data collection. Initial interviews were based on a broad framework, including the management, strategy and IS integration literatures, but with a particular focus on concepts related to the knowledge-based view of acquisitions (Haleblian \& Finkelstein, 1999; Zollo \& Winter, 2002; Zollo \& Singh, 2004). Interviews were semi-structured to facilitate the collection of data for both the deductive and inductive analyses (c.f. Eisenhardt, 1989). They were recorded and transcribed. Interviewees were selected, based on their ability to provide information on Trelleborg's acquisition IS integration experiences. 


\section{[Table 1]}

Additional data sources (see Table 1) were used to complement the interviews and to triangulate findings. Sensitive documents, including due diligence reports, internal evaluations and other strategic documents, were studied at the respective organisation's premises. Following Yin (1994), Table 2 summarises the measures taken to ensure reliability and validity throughout the research process.

\section{[Table 2]}

\section{Data analysis}

Consistent with the analytic induction process, data were analysed deductively and inductively. First, following a deductive approach, we analysed the data to determine the support for our initial propositions. A priori categories (Saldaña, 2009) representing the constructs and contingencies of propositions were used to code the empirical material (Table 3). Subsequently, data were coded with respect to relations between coding categories. The identified relations were matched with the mechanisms and contingencies suggested in our initial propositions (c.f. pattern matching, Yin, 1994).

[Table 3]

Second, following an inductive analysis strategy, we revisited the case data to identify additional theoretical insights regarding: a) category refinement of acquisition IS integration expertise and b) how routines and expertise were traceable to other learning mechanisms not covered by the initial propositions. Category refinement followed protocols from Saldana (2009) on coding refinement, based on the articulation of rules for inclusion in each subcategory. Coding to discover additional learning mechanisms of relevance was done with selective coding (Strauss and Corbin, 1998). Selective coding refers to 'the process of selecting the core category, systematically relating it to other categories, validating those relationships, and filling in categories that need further refinement and development' (Strauss and Corbin, 1998, p. 116). Categories of routines and expertise were held as core categories. Initial coding of passages containing information relating to the core categories but not captured in the deductive analysis was followed by coding clustering to find more generic themes (c.f. Strauss and Corbin, 1998; Saldana, 2009). Clustering was made with a constant comparison method (Strauss and Corbin, 1998). The emerging themes spurred a new literature search directed towards theoretical arguments in support of the empirical findings. Based on empirically induced findings and supportive theoretical arguments, new propositions were derived.

To integrate findings, we developed rich case stories supported by quotes and document references to ensure empirical support for the emerging stories. The rich cases were shared with employees of 
Trelleborg to get feedback on representativeness of findings. This feedback supported our conception of how Trelleborg built knowledge for acquisition IS integration.

\section{Case Description}

Trelleborg AB is an industry group with businesses based on processed polymer materials. In the period covered by this research, the group had approximately 22,000 employees in 40 countries. Annual sales were approximately $€ 3$ billion. The group's headquarters are located in the city of Trelleborg, Sweden. Trelleborg is committed to an $8-10 \%$ annual sales growth target over a business cycle. This has been achieved through a combination of organic growth and acquisitions of complementary businesses.

Trelleborg is a decentralised organisation with five business areas that enjoy extensive autonomy: Trelleborg Automotive (TA), Trelleborg Engineered Systems (TES), Trelleborg Wheel Systems (TWS), Trelleborg Building Systems (TBS), and Trelleborg Sealing Solutions (TSS). Each division of Trelleborg has its own distinct business, customer set and specific IS. TA, TBS and TSS use area-wide Enterprise Resource Planning (ERP) systems. In the group, the preferred ERP system is Movex - a Swedish standard package ERP system by Intentia, now part of Lawson Software. In TES and TWS, the business units are given autonomy to adopt the systems most appropriate for their customers and business processes. The central Group IT function makes decisions for network capacity, hardware, IT consulting services and IT outsourcing. The corporate website, the intranet and email are shared group services.

Trelleborg's acquisitions are generally based on the intention to grow business in a specific direction, in combination with what is available on the market. Table 4 presents the acquisition IS integration experiences for the four acquisitions that were of particular interest in the study. The four acquisitions manifest differences in a number of previous experiences, heterogeneity in previous experiences and presence of deliberate learning mechanisms in previous experiences.

[Table 4]

TES' acquisition of Kléber is an example of one of Trelleborg's early acquisitions. TES' acquisitions of Dynaflex and CRP, and TSS' acquisition of Chase-Walton are examples of Trelleborg's later acquisitions when Trelleborg had become an experienced acquirer.

The structural placement of the investigated acquisitions (Figure 4) was important because of its impact on heterogeneity in acquisition experiences. Three of the acquisitions were made by TES. TES carried out a very heterogeneous set of acquisitions representing a multitude of business rationales and IS integration strategies. In contrast, TSS had a homogenous business model spanning the whole business area. 
Business was divided into three activities: solutions design, logistics and production. Focus was on solutions design and logistics. TSS was expanding the business model organically and by acquisitions in attractive markets. Acquisitions were always driven by the same objectives and contingent on absorption into the solutions-oriented business model. Hence, the IS integration of Chase-Walton corresponded considerably to previous acquisition IS integration experiences.

\section{[Figure 4]}

The structural placement of the investigated acquisitions was also important because of its impact on the presence of deliberate learning mechanisms. TES, but not TSS, conducted systematic evaluation of its acquisition IS integration projects.

\section{Case analysis}

We present here the deductive and inductive analyses of how Trelleborg built routine-based and expertise knowledge. Table 5 provides a summary of routine-based and expertise knowledge. The deductive analysis finds support for the three initial propositions. Based on the inductive analysis, we refine the concept of acquisition IS integration expertise. We also develop two new propositions suggesting that knowledge relevant for acquisition IS integration may come from learning mechanisms of sub-activity refinement and related expertise building.

\section{[Table 5]}

\section{Deductive analysis}

\section{Routine refinement}

Routine refinement refers to the 'semi-automatic' (learning by doing) refinement of organisational routines while repeating similar tasks over and over again (Cohen et al., 1996). TSS' acquisition of Chase-Walton is an example of IS integration by a refined acquisition IS integration routine. Given TSS' homogenous business model, all acquired businesses were decomposed and absorbed into TSS' three functions of solutions design, logistics and production.

\footnotetext{
'When we acquire a company it is usually run in the usual way that it produces and sell parts to the end customer. ... In the integration of such an independent site we will take away the customer relationship activities and integrate that into the marketing organization. The logistics will eventually go to the SCM organization. ... When we [in IT] get involved it is to care of the IT infrastructure, bringing them onto the network, and making sure that their email system is compatible with ours. ... We then review the urgency to provide the production site with ERP type functionality. Usually there is no urgency, but if there is we can roll out our standard functionality in less than a week' (TSS Business developer M\&A unit).
} 
In TSS, organisational absorption was always accompanied by IS absorption. This type of acquisition was repeated over and over. By the time that Chase-Walton was acquired, TSS had refined its IS absorption routine to the point that the target's IS were no longer important.

'Because, no matter what they used, we'd be replacing their systems with our own ERP. If a company had systems that couldn't give us what we needed, we'd replace it in within the first week. It's not a feature of the process and it doesn't affect the acquisition decision what systems they have' (TSS CFO).

The process by which the routine was established resembles the 'semi-automatic,' learning-by-doing process described for experience curves (Cohen et al., 1996). At the time of Chase-Walton, this learning mechanism had reached a saturated state. The Chase-Walton sub-case emphasises the importance of homogenous experiences for this learning mechanism.

None of the three other acquisitions displayed the same routine-based knowledge developed from previous acquisitions. In the other business areas with their heterogeneous set of IS, each acquisition IS integration challenge proved a unique comparison to previous experiences. According to TES' CIO, TES' acquisition projects were so disparate that going into detail for each type of acquisition in an acquisition IS integration manual would be impossible, and general recommendations would be too general to be useful. However, as will be addressed later in this analysis, the Dynaflex acquisition presented an efficient routine, even though it was not gained from previous acquisition experiences.

As suggested by the literature on experience accumulation from previous acquisitions (Cohen \& Levinthal, 1990; Barkema et al., 1996), TSS repeatedly engaged in similar acquisitions, refined and mastered a specific IS integration routine. As suggested, the IS integration routine TSS refined was an IS absorption routine. Contrasting the routine refinement in TSS and TES, we conclude that the acquirer's pre-acquisition IS conditions and the employed strategies for acquisition IS integration consist of an important source for the level of homogeneity in acquisition experiences, and in consequence, for the possibilities for learning to do acquisitions by routine refinement. The case thus supports Proposition 1:

P1. Repeated acquisition IS integration addressing a homogenous set of IS integration challenges enables routine refinement and the establishment of an efficient IS integration routine for the specific IS integration challenge.

\section{Superstitious learning}

The risk of making incorrect interpretations of a routine's applicability is, according to the literature on superstitious learning (Levitt \& March, 1988; Zollo, 2009), high when the acquirer has limited experience that has not been formally evaluated. Then, facing a challenge that deviates from previous experiences, 
the organisation fails to recognise the critical difference and applies a previously successful routine which does not work as anticipated. The Kléber case illustrates this mechanism.

'We were not as experienced back then, in particular not with IT integration. In the acquisitions we had made, IT had not been an issue. At this time ERP systems were only becoming standard components of a business. I don't think anyone thought that IT could really be a hinder for to the operational integration. I mean, we never bought a company because of its IT system' (TES Business developer).

By the time of the Kléber acquisition, Trelleborg had made a few acquisitions to deliver scale-based benefits. Trelleborg had learned that it was essential to bring the acquired unit and the corresponding unit within the existing business onto common IS, thus supporting the unit's operations in order to realise the scale-based benefits. They had also learnt that this was effectively done from a starting point in the existing unit's Movex-based platform that was already connected to the corporation's technical platform with network capacity, outsourcing agreements and so on. Further, they could draw on an extensive pool of competence through their good relation with Intentia, the Movex supplier.

'They tried initially to use the Movex in Trelleborg as model. But, if you look at the specification ... they just wanted more of the same. That was not what we needed' (TIH Operations manager).

The conditions for wrongly applying a learned routine were ideal. Trelleborg had only completed a few acquisitions by this time and an even smaller subset with scale-based benefits. At this time, restructuring was at full pace, and people at the central business development department jumped from project to project, trying to keep up with demand. This gave no opportunity for formal evaluation.

Importantly, the Kléber case was different in a way that the Swedish management team, specialised in business and production rather than in IS, did not realise. The existing hose business ran a highly customized version of the Movex ERP system that was tailored to a small niche player. This system did not include the functionality to support the new scale-based strategy. Consequently, the acquisition of Kléber was not an acquisition that could be integrated by an IS absorption strategy. Trying to do so revealed how badly the routine matched the problem at hand.

'At the end of 1998 they arrived to the conclusion that it would take about 1000 working days to make the specific developments the outlined in for the new Movex system, to make the specific development on top of the standard system. ... It was too much. It couldn't be motivated with future savings' (TIH Operations manager).

Forcing the strategy would have caused additional IS development with costs significantly exceeding the expected scale-based benefits. The new management team decided that full IS integration had to wait until it was time to retire the Bergounix platform. In the meantime, they leveraged a minor subset of 
potential synergies by a full IS co-existence strategy and minor ad-hoc integration between the separate systems. It was ten years before the Bergounix-platform was retired and IS integration was finally completed.

'We had to do things in the right order... first turn around business in Kléber and prove that it worked. Then we could put the Trelleborg operations into our model' (TIH Operations manager).

The mechanism behind superstitious learning is founded on the logic that the acquirer is not aware of the limitations of the repeatedly refined routine (Zollo, 2009). According to Proposition 2, TSS would have been exposed to the high risk of applying the previously efficient IS absorption routine to address an IS integration challenge to which the routine did not match. However, in the TSS case, we found strong empirical evidence against this.

'If we were another company we would have integrated them differently, but for us it is essential to have them into our model. That's the kind of acquisition we can and should do' (TSS CFO).

'How we do IT integration fits with how we want to be growing. We want to grow with our model. To do so we must bring the business over to our systems. We know how to do that, its nothing complicated. Within a month they will be running on our systems' (TSS IT specialist M\&A unit).

In particular, the employees carrying out the IS integration projects were very aware of the limitations of the routine. This suggests that the problem of superstitious learning might not be that the knowledge did not exist in the organisation, but that it is not available when needed: pre-acquisition when estimating synergies and settling the deal. Surveys indicate that less than $25 \%$ of all acquirers include IS managers in the due diligence phase (Curtis \& Chanmugam, 2005). Solutions to superstitious learning should therefore be sought in the composition of the deal team and in strategies for internal communication.

I learnt about the [CRP] deal only weeks before it took place. This is how things go normally. You cannot prepare for everything; you discuss and plan for numerous deals simultaneously. Most of them will never take place in reality. Then one deal suddenly becomes reality and you have to deal with that one. I don't think anyone can foresee which deals that will become in the end' (TES CIO).

Theory suggested that a limited set of similar experiences creates conditions for establishing the incorrect knowledge that a well-functioning routine will fit to a problem to which it does not match (Zollo, 2009). This erroneous generalisation happened in Trelleborg during the conditions suggested by theory, given the effect suggested by theory. However, the Trelleborg case indicates that the knowledge for making a correct generalisation may well exist within the organisation, but when the people who know about the limitations of the routine are presented with the acquisition plans, it is too late for corrective action to be taken. This might explain how erroneous generalization is more likely to be avoided in acquirers that do 
formal evaluation of their acquisition integration projects (Zollo \& Singh, 2004). Given that the composition of the acquisition deal team in Trelleborg corresponds to the usual composition of a deal team, this finding may not be limited to erroneous generalisation at Trelleborg. Accepting this elaboration of the superstitious learning mechanism, the case data supports Proposition 2:

P2. Through superstitious learning, acquirers with a homogenous set of acquisition IS integration experiences risk incorrectly categorizing their IS integration experiences.

\section{Expertise building}

As described above, the process of expertise building resembles retrospective sense-making (Weick, 1995 ) in which the acquiring organisation, through reflection and evaluation (deliberate learning mechanisms; Zollo \& Singh, 2004) builds its conceptual framework for categorising and contextualising acquisition experiences (Levitt \& March, 1988; Bingham et al., 2009).

As the TIH unit was part of TES, TES's central IS function followed the integration of Kléber closely. At the time of the CRP acquisition, Trelleborg had completed more than 40 acquisitions, many of them within the TES area. All major IT investments had to go through TES's central IT function for approval. TES's IT function was thus able to follow all IS integration projects, being informed about the reasons for strategies chosen and causes of problem encountered. Failures and problems were evaluated and reflected upon.

'Every time we wanted to change something, I had to write a request explaining the need and how it would benefit the company. I think [we] made about 40 of them in total. Because of the trouble we had initially, the managers in Trelleborg were sceptical and followed what we did closely' (TIH Operations manager).

Regarding the CRP acquisition, there is evidence that TES had developed what Levitt and March (1988) referred to as a framework for categorising experiences.

'Compared to our previous acquisitions, the challenge in CRP was similar to when we acquired Kléber. It was similar in the way that they had an ERP system that could not support them long term. The difference was what we did about it. The final solution was very close to the process that eventually got Kléber integrated, but this time we avoided the initial problems' (TES CIO).

In the CRP acquisition, there is also evidence that TES had developed what Bingham et al. (2009) refer to as contextualisation abilities. TES were able to assess how the unique conditions for acquisition IS integration in their business area related to the alternatives for IS integration and applied to the acquisition at hand. For example, TES wanted to move some of its existing businesses to the new unit formed, but decided to wait until after the ERP system had been replaced. 
Because of the uncertainty, it was publicly announced that the acquisition was motivated by synergies in sales, marketing and distribution - benefits that could be realised without fully completing the integration project. If the conditions should permit IS absorption, the synergistic scope would be expanded. If not, synergies in production would have to wait. A more stressed acquirer might have been tempted to seek all potential benefits of the acquisition immediately, as Trelleborg did in the Kléber acquisition when the hose business was bleeding financially.

'There was another difference compared to Kléber. When we did that acquisition, both Trelleborg and Kléber were bleeding. Now Trelleborg can be a patient acquirer. And CRP was generally doing fine already. When we acquired CRP we were uncertain of when we could create these additional synergies. We knew we could, but we had no reason to rush the project'. (TES CIO)

Propositions $3 \mathrm{a}$ and $3 \mathrm{~b}$ described acquisition IS integration expertise as a conceptual framework that allows the acquirer to categorise and contextualise IS integration experiences. Several experiences and variations encountered were necessary but insufficient for building expertise. The case data support Propositions 3a and 3b:

P3a. Over time, contingent on variance in IS integration experiences and presence of deliberate learning mechanisms, acquirers can develop conceptual frameworks that allow them to categorise acquisition IS integration experiences.

P3b. Over time, contingent on variance in IS integration experiences and presence of deliberate learning mechanisms, acquirers can develop conceptual frameworks that allow them to contextualise acquisition IS integration experiences.

\section{Inductive analysis}

The inductive analysis consists of two parts. First, acquisition IS integration expertise is refined by: a) detailing the specific abilities that enable acquirers to categorise and contextualise IS integration experiences, and b) introducing the expertise category of Customisation (Proposition 3c). Second, we formulated Proposition 4 and 5 to reflect the importance of experiences other than acquisitions in the building of knowledge for acquisition IS integration.

\section{Refinement of acquisition IS integration expertise}

Levitt and March (1988) defined abilities for categorisation of experiences as key in building and using routines. Bingham et al. (2009) complemented this with abilities for contextualising options and routines. In the empirical study, we found instances of both these categories of abilities. Here, we analyse the four sub-cases to investigate how the categories of expert abilities can be refined into specific abilities for 
acquisition IS integration. The result of the refinement is presented in Table 6, which also presents a new, inductively derived, category of abilities: customisation abilities. The empirical evidence for this category is presented after the refinement of categorisation and contextualisation abilities.

\section{[Table 6]}

The Kléber acquisition displayed no evidence of expertise. In the Dynaflex case, the acquisition IS integration team displayed expertise in the sense that they understood how the standard routine would affect the target (representing a Customisation ability labelled as Routine implications, see Table 6). According to the existing routine, the production-related IS would have been replaced by the central IS. However, the IS manager recognised that imposing the full standard package would significantly reduce the flexibility and agility of Dynaflex as a small niche player. Instead of applying the full routine, the IS integration group regarded the routine as consisting of different modules that could be combined with modules of other routines (Categorisation ability: Module categorisation).

In the acquisition of CRP, TES were able to distinguish between the different routines employed for different types of acquisitions, as well as to see the similarities with the Kléber case (Categorisation ability: Routine categorisation). Compared with the Kléber case, TES decided that full consolidation of IS might have to wait until the next major platform update (Contextualisation ability: Problem anticipation). As explained by TES's CIO, Trelleborg's strong financial position at the time of the acquisition facilitated integration stamina (Contextualisation ability: Organisational contextualisation).

In TSS, acquisition IT integration expertise was demonstrated by an understanding of what the existing routine could be used for and what it could not do. This was recognised by TSS management who explained which acquisitions they could complete and which they would not be able to integrate with the existing routine (Contextualisation ability: Routine applicability). However, beyond the specific routine expertise, knowledge was limited. TSS knew they could not apply the existing routine, but did not know what to do instead. On the other hand, with the existing growth strategy, they had no reason to explore other types of acquisition IS integration routines. Acquisitions at TSS were not regarded as isolated events, but as acquisition programs. Consequently, IS integration was not regarded as comprising isolated events, but in a greater picture as IS integration programs (Categorisation ability: Program categorisation).

After grouping the expertise displayed into categorisation and contextualisation in the coding process, a group of expertise knowledge related to the tailoring of routines to meet minor variation in the challenge remained. In the acquisition of Dynaflex, TES was able to adapt a routine and improvise in the tasks not covered by routine-based knowledge (Customisation ability: Modification). In the acquisition of CRP, 
TES used different IS integration strategies for different functional areas. Whereas functions such as sales and distribution were integrated with IS co-existence, IS renewal was needed to complete integration of production. TES was able to combine different IS integration routines addressing different functional areas (Customisation ability: Combination). Finally, also in the CRP acquisition, rather than identifying and resolving all problems upfront, CRP used initial information about the targets' IS to outline potential issues to be resolved, given a specific IS integration strategy. The understanding of which problems could be encountered and the different options to address them made possible an initial broad approach to IS integration and subsequent improvisation (Customisation ability: Improvisation). Therefore we propose:

P3c. Over time, contingent on variance in IS integration experiences and presence of deliberate learning mechanisms, acquirers can develop conceptual frameworks that allow them to customize acquisition IS integration experiences.

\section{Sub-activity refinement}

When integrating Dynaflex, TES drew on experiences from implementing the Movex roll out, thus facilitating the integration of Dynaflex into TIH and TES. IS integration of Dynaflex took three months, which is very fast. Fast IS integration was essential, since the seller, Manuli, would keep its IS support only for six months. Importantly, the knowledge for the implementation part of this IS integration was developed through an internal IS integration project centralised on the Movex platform. For the people involved in the implementation, this was yet another project of the same type.

'We used existing processes that we had created for previous projects. I think that we only created one or two new processes' (TIH System integrator).

This suggests that it is possible to build knowledge relevant to acquisition IS integration from other related types of experiences. This finding resembles an identified pattern in the strategic management literature labelled as 'transfer effects' (Finkelstein \& Haleblian, 2002) or 'spillover effects' (Barkema \& Schijven, 2008a; Zollo \& Reuer, 2010). Spillover effects refer to a relationship between two organisational abilities where changes in the performance of one ability change the performance of another ability (Finkelstein \& Haleblian, 2002; Zollo \& Reuer, 2010).

Porrini (2004a) has shown a positive relationship between alliance experience and financial performance of acquisitions. She argues that 'alliances create opportunities for firms to gain a variety of experiences in exchanging and integrating resources with various similar and dissimilar partners and can inform integration of targets' (2004a, p. 268). However, Zollo and Reuer (2010) argue that alliance experience is beneficial only if the acquisition requires little integration, as alliances are not sources from which the acquirer can learn about integration. Zollo and Reuer present a survey of the U.S. banking industry to support their argument. This is in contradiction to Porrini's conclusions but in line with her empirical 
findings. Porrini's empirical data suggest that spillover effects are more prominent in acquisitions requiring low degrees of integration, compared to acquisitions requiring high degrees of integration.

The question is then: Apart from acquisitions, what experiences are relevant sources for learning about acquisition IS integration? Consistent with Zollo and Reuer (2010), Trelleborg used their experiences from long-term partners for the initial low-level IS integration of CRP.

'Integrating our systems to other systems is something we frequently do. It can be with suppliers, customers or organisations such as customs authorities. It's a technical task that we know how to do' (TES CIO).

We did not find evidence to the contrary that Trelleborg learned how to do more profound IS integration from their alliances. However, we found evidence that Trelleborg improved its IS integration routines from internal IS integration projects in the Dynaflex case. This seems to be consistent with the findings of Tanriverdi and Uysal (2011), who find that the extent to which the acquirer has, pre-acquisition, been able to integrate IS across the organisation, is correlated with the financial performance of its acquisitions. The authors believe that this is because internal IS integration comprises experiences from which the organisation can learn how to integrate IS in acquisitions.

The inductive analysis of Trelleborg suggests that apart from alliances and joint-ventures as learning possibilities for low-level integration acquisitions, internal restructuring and IT platform projects are important for learning how to do high-level integration acquisitions. This finding may improve the explanatory potential of the limited and inconsistent literature on spillover effects and acquisition integration (Porrini, 2004b; Zollo \& Reuer, 2010).

Importantly, the spillover effects we find are not of complete IS integration routines. The effects are related to specific tasks in the routines due to shared activities; for example, to the technical implementation in the Dynaflex case and the planning of the co-existence strategy in the CRP case. The mechanism by which this particular type of spillover effect unfolds is by the establishment of an effective routine to deal with a sub-activity shared between acquisition IS integration and some other IS challenge. In improving how to attend to the other IS integration, the organisation also improves its ability to address acquisition IS integration challenges, including this particular sub-activity. We therefore propose:

P4. Learning how to attend to other IS challenges can also improve IS integration routines because of shared sub-activities.

\section{Related expertise building}

Apart from the mechanism of sub-activity refinement, our inductive analysis indicates the possibility for another type of spillover effect. In the CRP case, Trelleborg learned that the IS renewal strategy takes 
time and is complex from previous acquisitions. This knowledge was also attributed to the internal IS implementation projects that had developed a general understanding of large IS implementations. However, they learned that the IS co-existence strategy is less complex but sufficient to enable synergies in marketing and sales. This knowledge partly came from the alliance experiences. When Trelleborg explained the reasons for not completing the full IS absorption of Dynaflex, the explanation included a joint venture experience that was supposed to be a flexible satellite, but could not operate in this way due to the IT solution chosen. TSS explained their confidence in the low risk of their IS absorption routine with examples of how they operated joint venture production units as stand-alone units when necessary. And what they could not do in these joint ventures was to have different sales systems, as that would limit their usefulness for TSS.

'You learn from everything you do. Sometimes its specific things such as to avoid a specific type of integration solution that you thought was good, or how to use a technology. But it can also be more general: How to appreciate risk, when you need a second opinion on a suggestion, what situations to avoid... I guess that you can see it as some sort of wisdom that come by age and experience' (TES CIO).

In our analysis, we could not relate the above given examples to any specific shared routine or activity. Instead, these are examples of how spillover effects (Barkema \& Schijven, 2008a; Zollo \& Reuer, 2010) also seem to affect acquisition IS integration expertise. Such experience spillover seems in the Trelleborg case to depend on the similarity among the managerial processes (cognitive proximity) that allow the acquirer to build abilities of categorisation, contextualisation and customisation. For example, in activities other than acquisitions Trelleborg developed the general ability to regard IS integration routines as a set of modules. This type of expertise ability was later used when regarding acquisition IS integration routines with higher granularity, suggesting spillover effects impacting contextualization expertise (c.f. Bingham et al., 2009). However, as our data collection was not primarily focused on related experiences, we do not have an exhaustive picture of how these activities formed part of the knowledge building.

Analysing the case, we note that there is a process of building acquisition expertise from experiences that seems to be cognitively close to acquisition challenges without directly sharing common sub-activities. We have not been able to unearth the full range of this influence, but propose a relation between acquisition IS integration expertise and a type of spillover effect based on cognitive proximity. Hence:

P5. Cognitive proximity between other IS challenges and the acquisition IS integration challenge can lead to spillover effects on acquisition IS integration expertise. 


\section{Discussion and Conclusions}

This section integrates theoretical and empirical findings into a knowledge-based model for acquisition IS integration. The boundary conditions of the model are then discussed. Finally, the theoretical contribution is discussed and implications for practice are explored.

\section{Findings}

Figure 5 summarises our view of how acquirers build knowledge for acquisition IS integration. Based on deductive and inductive analysis of Trelleborg, we find that two distinct types of organisational knowledge are relevant for acquisition IS integration: routine-based and expertise knowledge.

\section{[Figure 5]}

IS integration routines are coordinated, repetitive sets of organisational activities for IS integration (c.f. Nelson \& Winter, 1982; Miner, 1991). By repeating acquisitions with similar acquisition IS integration challenges, the acquirer can repeatedly employ the same IS integration strategy and, for this specific acquisition, can refine an efficient IS integration routine (Proposition 1). The developed routine is limited to the IS integration of one particular type of acquisition and provides limited support for acquisitions that deviate from the type of acquisition. This finding provides an explanation to the behaviour of successful serial acquirers, such as CEMEX and Banco Santander (Kanter et al., 2007; Parada et al., 2009).

Over time and under the condition that acquisition IS integration experiences display some degree of heterogeneity, serial acquirers can develop acquisition IS integration expertise (c.f. Levitt \& March, 1988; Bingham et al., 2009) (Propositions 3a, 3b, 3c). We explored organisational abilities associated with acquisition IS integration expertise and find ability categories of categorisation, contextualisation and customisation. Deliberate learning mechanisms (articulation and coding) reinforce the building of expertise through evaluation and reflection upon experiences (c.f. Zollo \& Singh, 2004). Acquisition expertise improves conditions for effective IS integration of non-routine acquisitions.

Organisations with limited expertise run the risk of incorrectly matching previously successful IS integration routines with challenges to which they do not match (Proposition 2). In doing so, they will deal with the challenge less effectively than would a novice acquirer without cognitive limitations. This effect is attributed to superstitious learning, referring to erroneous generalisations of previous experiences (Zollo, 2009).

Finally, our empirical study suggests that non acquisition-related experiences may be important sources for building knowledge for acquisition IS integration. In particular, the study identifies experiences from 
internal IS integration as an important source for learning how to implement IS integration strategies. Improvement in the execution of related tasks can spill over (Zollo \& Reuer, 2010) on the performance of IS integration routines through shared sub-activities (Proposition 4), and lead to IS integration expertise by cognitive proximity (Haleblian \& Finkelstein, 1999) in challenges (Proposition 5).

\section{Model boundary conditions}

The states covered by our knowledge-based model of acquisition IS integration range from the novice acquirer with only a few acquisition experience, to the skilled serial acquirer that has developed expertise and routines to analyse and implement appropriate IS integration in its acquisitions. However, in this research we have restricted the theoretical development to the class of serial acquirers that builds knowledge by, and for, the relatively simple acquisition of individual business units.

The restriction of the phenomenon analysed frames the constructs of the model: The acquisition experiences relate to IS integration of individual business units, the expertise and routines formed are for IS integration of individual business units and the related experiences discussed here are those experiences that may have an impact on knowledge for IS integration of individual business units. Similarly, the associations between these constructs, formulated as five propositions, also exist within the boundaries of the individual business unit acquisition. It follows that the more complex merger of equals and the acquisitions of multi-business organisations lies outside the boundaries of the model developed. Both are, from a knowledge-based view, much more complex events than the acquisition of a single business unit and should be addressed in subsequent research.

The explanation to how serial acquirers realize IT-based value in acquisitions is inevitable going to be multifaceted and complex - if the explanation was simple, then acquisition IS integration would not present such a challenge to acquiring companies. The research in this paper should be seen as first step in reframing the study of acquisition IS integration from the view of acquisition IS integration as an isolated event, towards a more holistic view seeking explanation to how an acquisition IS integration project impacts and is impacted other organisational activities. The knowledge-based perspective emphasises the role of the knowledge-resource, downplaying other qualities of the IT resource that can be of relevance for the acquisition IS integration. For example, Henningsson et al. (2007) note that a modular architecture may facilitate acquisition IS integration. The IT resource itself as enabling or constraining acquisition IS integration strategies is one important area for subsequent research, but a range of additional perspectives are needed to fully appreciate the challenge and how it can be overcome. As no single theoretical framework can by itself explain the complex IS integration challenge of acquisition programs, research needs to pursue multiple theoretical perspectives that emphasise different aspects of the challenge. 


\section{Theoretical contributions}

Studying acquisitions as isolated events, previous research has identified important differences in acquirers' abilities for acquisition IS integration, but has provided limited explanation to these differences (e.g., Stylianou et al., 1996; Robbins \& Stylianou, 1999; Tanriverdi \& Uysal, 2011). The model of how serial acquirers over time build knowledge for acquisition IS integration presents an explanation of the differences and how they arise. The knowledge-based explanation contrasts previous research on ITbased value creation in acquisitions that has principally explored characteristics of the acquisition IS integration challenges. No previous research has explored how serial acquirers' abilities for acquisition IS integration evolve over a series of acquisitions.

Knowledge-resources for acquisition IS integration are not resources that can be easily transferred, acquired or sourced. Parts of the knowledge-based literature (e.g., Kogut \& Zander, 1992; Spender, 1996) argue that organisational knowledge should be seen as a process of on-going social construction. Our study echoes this conclusion. Participation and self-experience recurred in the explanations for knowledge building in Trelleborg. Whereas some general knowledge about how to analyse and implement acquisitions can be sourced from specialists, the IS-related knowledge seems to be particular in the way that it requires a deep understanding of the own IT infrastructure, and thus, cannot be sourced from the external. The consequence is that knowledge necessary for attending to an IS integration challenge has to be built over a series of acquisitions. To the extent that differences in acquirers' abilities for acquisition IS integration depend on knowledge variations, these differences may therefore be persistent and hard to overcome for the inexperienced acquirer. On the other hand, for acquirers such as Danisco, CEMEX and Banco Santander, the knowledge that they possess for acquisition IS integration would comprise a source for competitive advantage that is difficult to imitate. Future research should further investigate the persistence of this advantage, including to what extent knowledge necessary for acquisition IS integration can be built from other experiences than acquisitions, or sourced from the external of the organization.

Adding to the general literature by building on a knowledge-based view on acquisitions (Zollo \& Singh, 2004; Capron et al., 1998; Bingham et al., 2009; Zollo, 2009; Zollo \& Reuer, 2010), our knowledgebased model of acquisition IS integration contributes in two ways. First, we extend the scope of challenges that need to be addressed when considering learning to acquire. Aspects specific to the IS integration challenge are not considered in this literature (Barkema \& Schijven, 2008a). We show that the learning processes identified are also applicable to acquisition IS integration. As we cannot expect learning to be automatic (Barkema \& Schijven, 2008a), it is essential to identify all tasks that benefit from directed learning attempts to explain variations in how acquisition knowledge is developed. We also analyse how the contingencies translate specifically to the IS integration challenge. In doing so, we extend the understanding about which situations lead to critical levels of frequency, 
homogeneity/heterogeneity and deliberate learning mechanisms in experiences. While the general mechanisms of learning are general, the contingencies associated with learning IS integration are specific. It is not necessarily true that what creates a set of homogenous experiences from a cultural or business process perspective will also lead to homogenous experiences from an IS integration perspective. It is therefore essential to assess the contingencies specifically for each critical acquisition challenge to achieve precision in explanatory models.

Second, studying the learning processes longitudinally in an in-depth case study in a previously unexplored context (IS integration) enables a richer understanding for how the learning mechanisms unfold (see the analysis above). In particular, we detail abilities for integration expertise (including the new ability category of customisation abilities linking expertise to routine-based knowledge), and find empirical evidence that the erroneous generalisation in superstitious learning might actually be a problem of knowledge transfer.

\section{Practical implications}

For acquirers, understanding the types of knowledge associated with different IS integration challenges helps in three areas. First, it identifies those targets that would be either easy or difficult to integrate for the potential acquirer, given the acquirer's existing knowledge base. Rather than accept the difficult IS integration challenges that do not correspond to the acquirers' knowledge base, acquirers may opt to search for targets that fit with acquisition IS experiences.

The second area in which this paper provides help is in identifying the challenges to be overcome when a potentially problematic acquisition is acquired. This includes avoiding the inappropriate application of a previously successful routine and the potential need to adapt and combine routines, as well as improvising if the challenge is found not to match the applied routine.

Third, a growing number of companies are moving away from regarding acquisitions as isolated strategic actions; instead, companies talk about acquisition programs that involve a series of strategic acquisitions (Laamanen \& Keil, 2008; Haleblian et al., 2009). This research shows that organisations can actively, by reflection and evaluation, develop acquisition IS integration knowledge (routine-based and expertise) that matches the acquisition program, and that such knowledge will contribute to the success of the program. The model in Figure 5 can be used as a framework for evaluation of, and reflection on, how organisations position themselves to the knowledge needs of their acquisition program. The identification of two different knowledge types and the mechanisms by which they are reinforced gives a foundation for IS management to act proactively, rather than reactively, with respect to abilities for acquisition IS integration. 


\section{References}

Al Mosawi A, Zhao L and Macaulay L (2006) A model driven architecture of enterprise application integration. In HICSS'39.

ALARANTA M and HENNINGSSON S (2008) An approach to analyzing and planning post-merger is integration: Insights from two field studies. Information Systems Frontiers 10(3), 307-319.

BARKema HG, Bell JHJ and Pennings JM (1996) Foreign entry, cultural barriers, and learning. Strategic Management Journal 17(2), 151-166.

BARKEMA HG and SCHIJVEN M (2008a) How do firms learn to make acquisitions? A review of past research and an agenda for the future. Journal of Management 34(3), 594.

BARKEMA HG and SCHIJVEN M (2008b) Toward unlocking the full potential of acquisitions: The role of organizational restructuring. Academy of Management Journal 51(4), 696-722.

BARLEY SR (1988) The social construction of a machine: Ritual, superstition, magical thinking and other pragmatic responses to running a ct scanner. In Knowledge and practices in medicine: Social, cultural and historical approaches (LOCK M and GORDON D, Eds), pp 497-539, Reidel, Hingham, MA.

BARNEY JS (1991) Firm resources and sustained competitive advantage. Journal of Management, 99-120.

BINGHAM CB, EISENHARDT KM and DAVIS JP (2009) Opening the black box of organizational expertise: Understanding what firms learn from their process experience and how that learning unfolds over time. Strategic Entrepreneurship Journal,

BRUELLER N and CAPRON L (2010) Cisco systems: New millennium - new acquisition strategy? INSEAD teaching cases,

BöHM M, HenNingsson S, Leimeister JM, YetTon P and KRCMAR H (2011) A dual view on it challenges in corporate acquisitions and divestments. International Conference on Information Systems, Shanghai, China.

CARlSSon SA, Henningsson S, Hrastinski S and Keller C (2011) Socio-technical is design science research: Developing design theory for is integration management. Information Systems and EBusiness Management 9(1), 109-131.

CAPRON L, DusSAUge P and MitChell W (1998) Resource redeployment following horizontal acquisitions in europe and north america, 1988-1992. Strategic Management Journal 19(7), 631-661.

CLEMONS EK and ROW MC (1991) Sustaining it advantage: The role of structural differences. MIS Quarterly 15(3), 275-293.

COHEN MD and BACDAYAN P (1994) Organizational routines are stored as procedural memory: Evidence from a laboratory study. Organization Science 5(4), 554-568.

Cohen MD, Burkhart R, Dosi G, Egidi M, Marengo L, Warglien M and Winter S (1996) Routines and other recurring action patterns of organizations: Contemporary research issues. Industrial and corporate change 5(3), 653.

COHEN WM and LEVINTHAL DA (1990) Absorptive capacity: A new perspective on learning and innovation. Administrative Science Quarterly 35(1), 128-152.

CURTIS GA and CHANMUGAM R (2005) Reconcilable differences: It and post-merger integration. Accenture Outlook 2, 81-85.

CYERT RM and JAMES G (1963) A behavioral theory of the firm. Prentice-Hall, Englewood Cliffs, NJ.

DAY DV and LORD RG (1992) Expertise and problem categorization: The role of expert processing in organizational sense making. Journal of Management Studies 29(1), 35-47.

ERICSSON KA and SMITH J (1991) Toward a general theory of expertise: Prospects and limits. Cambridge Univ Press, Cambridge, UK.

EVGENIOU T (2002) Information integration and information strategies for adaptive enterprises. European Management Journal 20(5), 486-494.

FELDMAN R (2002) Epistemology. Prentice Hall, Upper Saddle River, NJ.

FOWLER KL and SCHMIDT D (1989) Determinants of tender offer post-acquisition financial performance. Strategic Management Journal 10, 339-350.

GAVETti G, LeVInTHAL DA and RIVKIN JW (2005) Strategy making in novel and complex worlds: The power of analogy. Strategic Management Journal 26(8), 691-712. 
Henningsson: "Learning to acquire" (Accepted pre-edition version)

European Journal of Information Systems advance online publication 8 July 2014; doi: 10.1057/ejis.2014.18

GEORGE AL and BENNETT A (2004) Case studies and theory development in the social sciences. MIT Press, London.

Giacomazzi F, Panella C, Pernici B and Sansoni M (1997) Information systems integration in mergers and acquisitions: A normative model. Information \& Management 32, 289-302.

GLYNN MA, LANT TK and MILIKEN MJ (1994) Mapping learning processes in organizations. In Advances in managerial cognition and organizational information processing (STUBBERT C, MEINDL JR and PORAC JFA, Eds), pp 43-83, JAI Press, Oxford, UK.

GRANT RM (1996) Toward a knowledge-based theory of the firm. Strategic Management Journal 17, 109-122.

GREGOR S (2006) The nature of theory in information systems. MIS Quarterly 30(3), 611-642.

Haleblian J, Devers CE, MCNAMARA G, CARPENTER MA and DAVISON RB (2009) Taking stock of what we know about mergers and acquisitions. Journal of Management 35(3), 469.

HALEBLIAN J and FINKELSTEIN S (1999) The influence of organizational acquisition experience on acquisition performance: A behavioral perspective. Administrative Science Quarterly 44, 29-56.

Haleblian JJ, Kim J-YJ and RaJagopalan N (2006) The influence of acquisition experience and performance on acquisition behavior: Evidence from the us commercial banking industry. Academy of Management Journal 49(2), 357-370.

HAYWARD MLA (2002) When do firms learn from their acquisition experience? Evidence from 1990 to 1995. Strategic Management Journal 23(1), 21-39.

HENNINGSSON S and CARLSSON SA (2011) The dysiim model for managing is integration in mergers and acquisitions. Information Systems Journal 21(5), 441-476.

HENNINGSSON S, RUKANOVA B and HRASTINSKI S (2010) Resource dependency in socio-technical information systems design research. Communication of the AIS 27(4),

HENNINGSSON S, SVENSSON C and WALLÉN L (2007) Mastering the integration chaos following frequent M\&As: Is integration with soa technology. In 40th Hawaii International Conference on System Science Waikoloa, Hawaii, US.

Hitt M, King D, Krishnan H, Makri M, Schijven M, Shimizu K and Zhu H (2009) Mergers and acquisitions: Overcoming pitfalls, building synergy, and creating value.

JOHNSTON KD and YETTON PW (1996) Integrating information technology divisions in a bank merger fit, compatibility and models of change. The Journal of Strategic Information Systems 5(3), 189-211.

KANTER RM, YATSKO P and RAFFAELLI R (2007) Cemex (a): Building the global framework (19852004). Harvard Business Review Cases, Harvard Business School.

KARIM S and MitchelL W (2000) Path-dependent and path-breaking change: Reconfiguring business resources following acquisitions in the us medical sector, 1978-1995. Strategic Management Journal 21(10-11), 1061-1081.

KeIL T, LAAMANEN T and MÄKISALO A (2012) Acquisitions, acquisition programs and acquisition capabilities. The Handbook of Mergers and Acquisitions, 148.

Ketterer H, Grebe M, Platt J and George M (2009) The seven elements of effective it integration. Boston Consulting Group.

KLEIN HK and MYERS MD (1999) A set of principles for conducting and evaluating interpretive field studies in information systems. Management Information Systems Quarterly 23(1), 67-93.

LAAMANEN T and KeIL T (2008) Performance of serial acquirers: Toward an acquisition program perspective. Strategic management journal. 29(6), 663-672.

LEE A (2010) Retrospect and prospect: Information systems research in the last and next 25 years. Journal of Information Technology 25, 336-348.

LEVITT B and MARCH JG (1988) Organizational learning. Annual Review of Sociology 14, 319-340.

MARCH JG (1991) Exploration and exploitation in organizational learning. Org. Science 2(1), 71-87.

MARKUS ML (2000) Paradigm shifts - e-business and business/systems integration. Communication of the AIS 4(10), 1-45.

MASSETTI B and ZMUD RW (1996) Measuring the extent of edi usage in complex organizations: Strategies and illustrative examples. MIS Quarterly 20(3), 331-345. 
MEHTA M and HIRSCHHEIM R (2007) Strategic alignment in mergers \& acquisitions: Theorizing is integration decision making. Journal of the Association for Information Systems 8(3), 143-174.

MERALI Y and MCKIERNAN P (1993) The strategic positioning of information systems in post-acquisition management. Journal of Strategic Information Systems 2(2), 105 - 124.

MINER AS (1991) Organizational evolution and the social ecology of jobs. American Sociological Review 56(6), 772-785.

NELSON RR and WINTER SG (1982) An evolutionary theory of economic change. Belknap press.

NONAKA I (1994) A dynamic theory of organizational knowledge creation. Organization Science 5(1), 14-37.

Parada P, Alemany L and Planellas M (2009) The internationalisation of retail banking: Banco santander's journey towards globalisation. Long Range Planning 42(5), 654-677.

PATTON MQ (2002) Qualitative research and evaluation methods. Sage, Thousand Oaks, CA.

PETERAF MA (1993) The cornerstones of competitive advantage: A resource-based view. Strategic Management Journal 14(3), 179-192.

Polanyi M (1966) The tacit dimension. Anchor Day Books, New York, NY.

PORRINI P (2004a) Alliance experience and value creation in high-tech and low-tech acquisitions. The Journal of High Technology Management Research 15(2), 267-292.

PORRINI P (2004b) Can a previous alliance between an acquirer and a target affect acquisition performance? Journal of Management 30(4), 545.

RoBBINS SS and STYLIANOU AC (1999) Post-merger systems integration: The impact on is capabilities. Information \& Management 36, 205-212.

ROBERTSON D, HEINCKIENS P and Ross JW (2007) The hidden demon - how it foils acquisition success. Perspectives for managers 2007(144), 1-4.

SALDAÑA J (2009) The coding manual for qualitative researchers. Sage, Los Angeles, CA.

SARRAZIN H and WEST A (2011) Understanding the strategic value of it in m\&a. McKinsey Quarterly (January)

SIMON HA (1955) A behavioral model of rational choice. The quarterly journal of economics 69(1), 99.

SPENDER JC (1996) Making knowledge the basis of a dynamic theory of the firm. Strategic Management Journal 17, 45-62.

StYlianou AC, JefFries CJ and RoBbins SS (1996) Corporate mergers and the problem of is integration. Information \& Management 31, 203-213.

TANRIVERDI H and UYSAL VB (2011) Cross-business information technology integration and acquirer value creation in corporate mergers and acquisitions. Information Systems Research 22(4),

VAN DE VEN AH (1992) Suggestions for studying strategy process: A research note. Strategic Management Journal 13, 169-191.

Voss I (2007) $M$ and a capability evolution. Cuvillier Verlag.

WADE M and HULLAND J (2004) Review: The resource-based view and information systems research: Review, extension, and suggestions for future research. MIS Quarterly 28(1), 107-142.

WEICK KE (1995) Sensemaking in organizations. Sage Publications, Inc.

Wijnhoven F, Spil T, StegWee R and FA RTA (2006) Post-merger it integration strategies: An it alignment perspective. The Journal of Strategic Information Systems 15(1), 5-28.

YELLE LE (1979) The learning curve: Historical review and comprehensive survey. Decision Sciences $10(2), 302-328$.

YETTON P, HENNINGSSON S and BJORN-ANDERSEN N (2013) Ready to acquire: The it resources required for a growth-by-acquisition business strategy. MIS Quarterly Executive 12(1), 19-35.

ZOLLO M (2009) Superstitious learning with rare strategic decisions: Theory and evidence from corporate acquisitions. Organization Science 20(5), 894-908.

ZOLLO M and REUER JJ (2010) Experience spillovers across corporate development activities. Organization Science 21(10), 1195-1212.

ZOLLO M and SINGH H (2004) Deliberate learning in corporate acquisitions: Post-acquisition strategies and integration capability in U.S. Bank mergers. Strategic Management Journal 25(13), 1233-1257.

ZOLLO M and WINTER SG (2002) Deliberate learning and the evolution of dynamic capabilities. Organization Science, 339-351. 


\section{Figures}

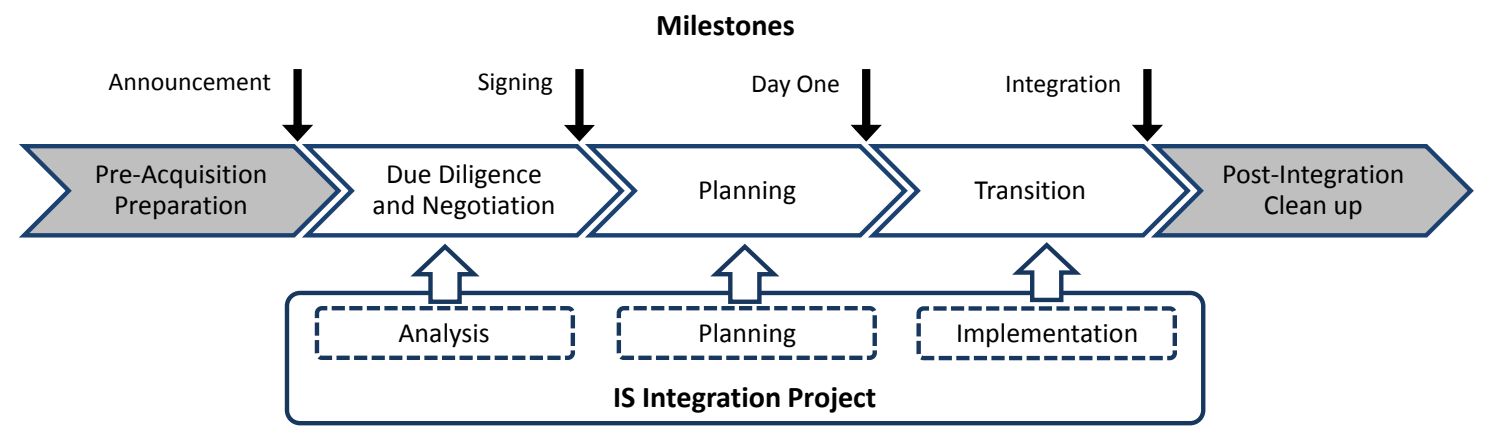

Figure 1. Generic model of the acquisition process and related IS integration activities
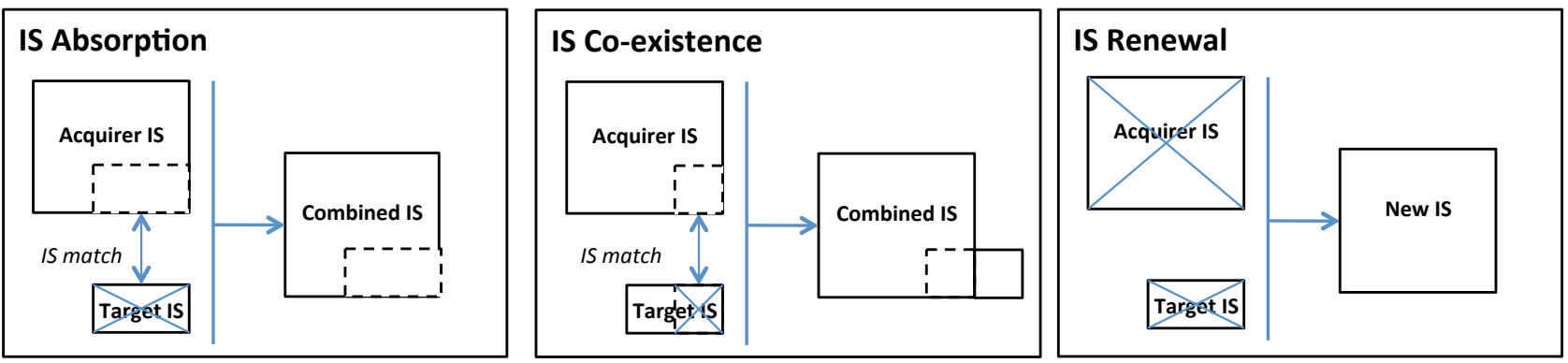

Figure 2. Three strategies for acquisition IS integration

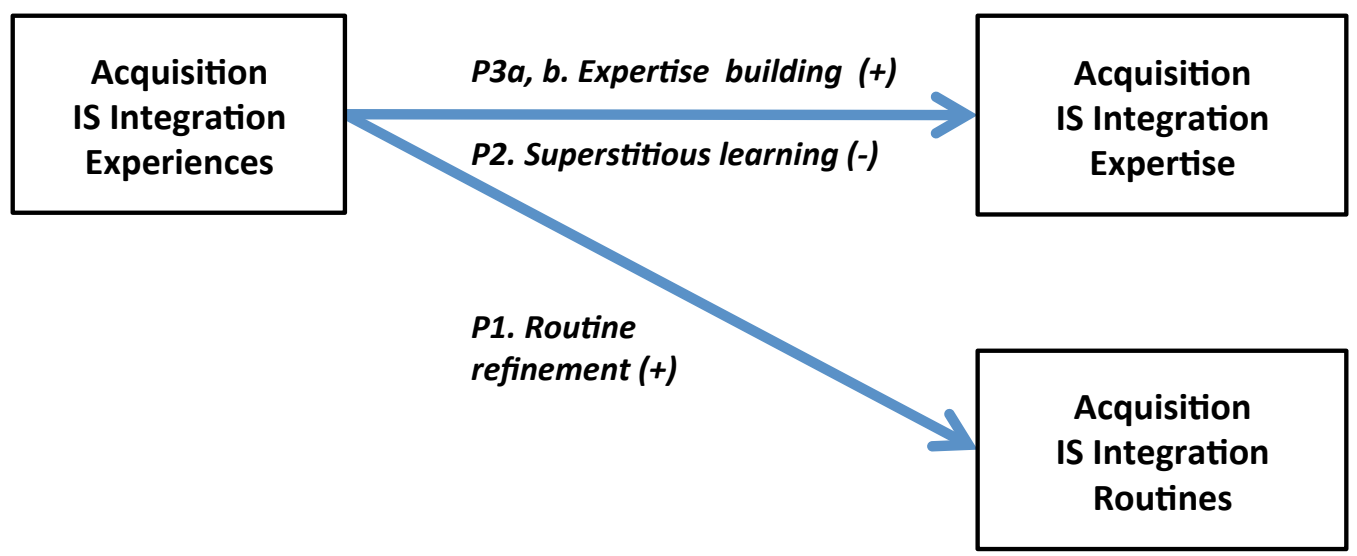

Figure 3. Initial knowledge-based model of post-acquisition IS integration 


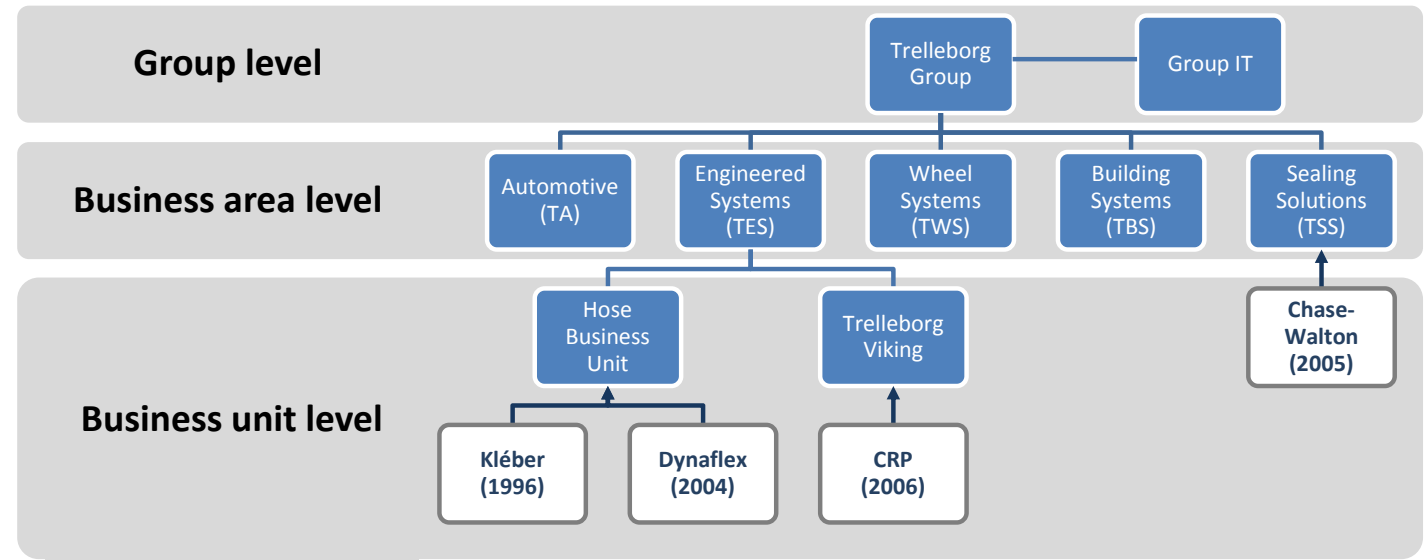

Figure 4. Structural placement of the four acquisitions in the study

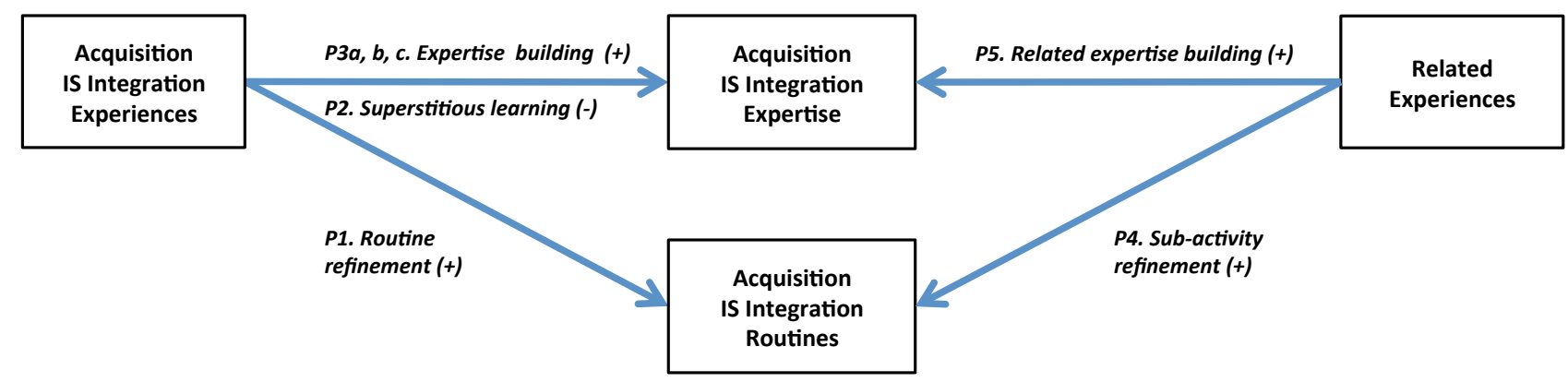

P1. Repeated acquisition IS integration addressing a homogenous set of IS integration challenges enables routine refinement and the establishment of an efficient IS integration routine for the specific IS integration challenge.

P2. Through superstitious learning, acquirers with a homogenous set of acquisition IS integration experiences risk incorrectly categorizing their IS integration experiences.

P3a. Over time, contingent on variance in IS integration experiences and presence of deliberate learning mechanisms, acquirers can develop conceptual frameworks that allow them to categorise acquisition IS integration experiences.

P3b. Over time, contingent on variance in IS integration experiences and presence of deliberate learning mechanisms, acquirers can develop conceptual frameworks that allow them to contextualise acquisition IS integration experiences.

P3c. Over time, contingent on variance in IS integration experiences and presence of deliberate learning mechanisms, acquirers can develop conceptual frameworks that allow them to customize acquisition IS integration experiences.

P4. Learning how to attend to other IS challenges can also improve IS integration routines because of shared sub-activities.

P5. Cognitive proximity between other IS challenges and the acquisition IS integration challenge can lead to spillover effects on acquisition IS integration expertise.

Figure 5. The knowledge-based model of acquisition IS integration 


\section{Tables}

Table 1. Overview of empirical data and case selection

\begin{tabular}{|c|c|c|c|}
\hline Case & Interviews & Additional data & Selection criteria \\
\hline General & $\begin{array}{l}\text { CIO (2), Head of } \\
\text { Business } \\
\text { Development, } \\
\text { Analyst Business } \\
\text { Development (2) }\end{array}$ & $\begin{array}{l}\text { Annual feedback sessions from 2004- } \\
2008 \text { (4), annual and periodic reports, } \\
\text { visits to headquarters, group } \\
\text { discussions. }\end{array}$ & $\begin{array}{l}\text { Large amount of acquisition experiences. } \\
\text { Prospect for drilling down into IS } \\
\text { integration expertise. }\end{array}$ \\
\hline Kléber & 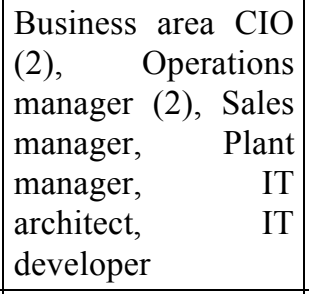 & $\begin{array}{l}\text { Business area headquarter, plant, } \\
\text { logistic centre and warehouse visits, } \\
\text { project plans, internal communication, } \\
\text { financial reports, investment requests, } \\
\text { system architecture blueprints, } \\
\text { systems documentation, IT } \\
\text { infrastructure chart, user guides. }\end{array}$ & $\begin{array}{l}\text { Finished case with substantial IS } \\
\text { integration to pilot the framework's ability } \\
\text { to capture IS integration. Rich picture of } \\
\text { what Trelleborg was able to do in } 1996 .\end{array}$ \\
\hline Dynaflex & $\begin{array}{|lr|}\text { Business } & \text { area } \\
\text { Operations } & \\
\text { manager, } & \mathrm{IT} \\
\text { architect } & (2), \\
\text { System } & \text { integrator } \\
(2) & \\
\end{array}$ & $\begin{array}{l}\text { Business area headquarter, plant and } \\
\text { warehouse visits, project plans, } \\
\text { internal communication, architecture } \\
\text { blueprints, systems documentation, IT } \\
\text { infrastructure chart, user guides. }\end{array}$ & $\begin{array}{l}\text { Recently finished case with fresh data, } \\
\text { making recreating of integration process } \\
\text { easier. According to Trelleborg a case } \\
\text { with extensive re-use of knowledge. }\end{array}$ \\
\hline $\begin{array}{l}\text { Chase- } \\
\text { Walton }\end{array}$ & 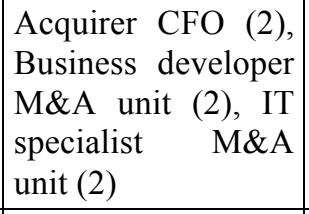 & $\begin{array}{l}\text { Business area headquarter and M\&A } \\
\text { unit visits, project plans, architecture } \\
\text { blueprints, systems documentation, IT } \\
\text { infrastructure chart, assessments, due- } \\
\text { diligence reports. }\end{array}$ & $\begin{array}{l}\text { On-going case in final stages with a } \\
\text { fundamentally different approach to IS } \\
\text { integration, taking place in a different } \\
\text { division by Trelleborg and involving } \\
\text { different individuals. }\end{array}$ \\
\hline CRP & $\begin{array}{l}\text { Business area } \\
(4), \quad \text { CIO } \\
\text { architect }\end{array}$ & $\begin{array}{l}\text { Business area headquarter visit, M\&A } \\
\text { unit visit, project plans, architecture } \\
\text { blueprints, project plans, meeting } \\
\text { protocols. }\end{array}$ & $\begin{array}{l}\text { On-going case in initial stages. Similar } \\
\text { challenges to Kléber case, but different } \\
\text { solution, based on previous experiences, } \\
\text { according to Trelleborg. }\end{array}$ \\
\hline
\end{tabular}


Table 2. Measures to ensure research reliability and validity (based on Yin, 1994)

\begin{tabular}{|l|l|}
\hline Reliability & Validity \\
\hline Case study protocols & Multiple sources of evidence \\
\hline - List of acquisitions & - See Table 1. \\
- Organisational charts with potential informants & Establishing chain of evidence \\
- Interview guide with areas of interest & - Extended case stories with extensive use of quotes \\
- Strategy to allow for new information & - Key findings of knowledge and learning mechanism \\
- Strategies for different informant competences & linked to specific quotes \\
- Risk areas with potential personal interests & Review of case drafts \\
Case study database & - Draft case stories were shared with employees of \\
\hline - Audio recording, transcriptions & $\begin{array}{l}\text { Trelleborg. Feedback corrected minor misconceptions } \\
\text { of how processes unfolded, but supported our } \\
\text { - Project documentation }\end{array}$ \\
- Field notes with potential alternatives & acquisition IS integration. \\
- Outcomes of reviews and informal discussions &
\end{tabular}

Table 3. Categories and codes in deductive analysis

\begin{tabular}{|l|l|}
\hline Category & Codes \\
\hline $\begin{array}{l}\text { IS integration } \\
\text { experiences }\end{array}$ & IS absorption, IS co-existence, IS renewal \\
\hline Knowledge types & $\begin{array}{l}\text { IS integration expertise (categorization, contextualisation), IS integration routines } \\
\text { (absorption, co-existence, renewal) }\end{array}$ \\
\hline Learning mechanisms & Expertise building, Superstitious learning, Routine refinement \\
\hline Process contingencies & Experience heterogeneity, Experience frequency, Deliberate learning efforts \\
\hline
\end{tabular}


Table 4. Sub-case figures and descriptions

\begin{tabular}{|c|c|c|c|}
\hline \multicolumn{2}{|c|}{$\begin{array}{l}\text { Acquisition } \\
\text { details }\end{array}$} & Business rationale & IS integration project \\
\hline \multicolumn{4}{|l|}{ Kléber } \\
\hline Year & 1996 & \multirow{7}{*}{$\begin{array}{l}\text { In 1996, Kléber was an } \\
\text { acquisition by the TES } \\
\text { division to build a scale-based } \\
\text { business in the hose industry. } \\
\text { The existing hose business was } \\
\text { limited in scope, trying to be a } \\
\text { niche player, but bleeding } \\
\text { financially. Importantly, } \\
\text { Kléber was four times larger } \\
\text { than the corresponding unit in } \\
\text { TES. TES expected economies } \\
\text { of scale to be realised in } \\
\text { production, sales and } \\
\text { distribution by combining the } \\
\text { existing hose business with } \\
\text { Kléber into the new unit } \\
\text { Trelleborg Industrial Hose } \\
\text { (TIH). }\end{array}$} & \multirow{7}{*}{$\begin{array}{l}\text { With respect to IS, Kléber was run as an independent company, with a } \\
\text { platform based on the in-house developed ERP system Bergounix. There } \\
\text { was no hard deadline for IS integration, but the anticipated scale benefits } \\
\text { were dependent on IS integration. To enable economies of scale, TES } \\
\text { tried to port Kléber onto the Movex (an ERP system by Intentia) based } \\
\text { platform used by the existing TES hose business. However, the proposed } \\
\text { action was cancelled in 1998. The Movex platform used by TES was } \\
\text { customised to meet the requirements of the old hose business niche } \\
\text { strategy. It did not support the scale-based operations of the combined } \\
\text { unit. Although the two units seemed to use similar IS, enabling an IS } \\
\text { absorption strategy, this strategy was discovered to not match the needs } \\
\text { of the combined unit. The acquisition required an IS renewal strategy to } \\
\text { realise acquisition benefits. } \\
\text { Kléber kept its Bergounix-based platform in a temporary co-existence IS } \\
\text { integration strategy. Later, the Bergounix platform, which was expensive } \\
\text { to maintain and extend, was replaced by a central, standard Movex } \\
\text { system. The old Trelleborg hose business was ported to the new Movex } \\
\text { system in } 2005 \text { to complete the IS renewal strategy. Costs were lowered } \\
\text { and TIH became profitable. } \\
\text { By } 2009 \text {, the combined hose business was supported by a shared } \\
\text { platform. }\end{array}$} \\
\hline Price $(€)$ & $40 \mathrm{M}$ & & \\
\hline Seller & $\begin{array}{l}\text { Michelin } \\
\text { (FR) }\end{array}$ & & \\
\hline Business & $\begin{array}{l}\text { Industrial } \\
\text { hose }\end{array}$ & & \\
\hline Sales $(€)$ & $60 \mathrm{M} \mathrm{pa}$ & & \\
\hline \multirow[t]{2}{*}{$\begin{array}{l}\text { Unit } \\
\text { emp. }\end{array}$} & 750 & & \\
\hline & & & \\
\hline \multicolumn{4}{|l|}{ Dynaflex } \\
\hline Year & 2004 & \multirow{6}{*}{$\begin{array}{l}\text { In 2004, TES made a second } \\
\text { acquisition in the hose } \\
\text { industry, acquiring the small } \\
\text { niche-player Dynaflex. By that } \\
\text { time, TES's hose business was } \\
\text { profitable with a low cost } \\
\text { position in the industrial hose } \\
\text { market. The Dynaflex } \\
\text { acquisition introduced new } \\
\text { production that could be used } \\
\text { more effectively by TIH's } \\
\text { distribution network. The } \\
\text { strategic intent was to grow } \\
\text { Dynaflex's business using } \\
\text { TES's resources, for example } \\
\text { by launching its products in } \\
\text { new markets where TIH had a } \\
\text { strong position. }\end{array}$} & \multirow{6}{*}{$\begin{array}{l}\text { TES employed a partial IS co-existence strategy to integrate Dynaflex' } \\
\text { IS. Dynaflex' IS for production were retained independently, but IS } \\
\text { supporting sales and distribution were ported onto TIH's Movex-based } \\
\text { ERP system. Two people from the team that previously had implemented } \\
\text { the centralised Movex platform were asked to extend it to embrace } \\
\text { Dynaflex also. They ported customer and product data to the Movex } \\
\text { system. The production facility was introduced as another production } \\
\text { facility in the central system, and the production system was integrated } \\
\text { with basic peer-to-peer architecture in three months. According to the } \\
\text { team, they just had to create another production facility in the Movex } \\
\text { system in the very same way as they already had done several times } \\
\text { before. } \\
\text { By } 2009 \text {, most functions were ported to the shared platform. Production } \\
\text { systems were kept separated and integrated with middleware. }\end{array}$} \\
\hline Price $(€)$ & $15 \mathrm{M}$ & & \\
\hline Seller & $\begin{array}{l}\text { Manuli } \\
\text { (IT) }\end{array}$ & & \\
\hline Business & $\begin{array}{l}\text { Specialty } \\
\text { hose }\end{array}$ & & \\
\hline Sales $(€)$ & $15 \mathrm{M} \mathrm{pa}$ & & \\
\hline $\begin{array}{l}\text { Unit } \\
\text { emp. }\end{array}$ & 50 & & \\
\hline \multicolumn{4}{|c|}{ Chase-Walton } \\
\hline Year & 2005 & \multirow{2}{*}{$\begin{array}{l}\text { Chase-Walton, until } 2005 \text { a } \\
\text { North-American } \quad \text { based } \\
\text { production-oriented actor in } \\
\text { the sealing and damping }\end{array}$} & \multirow{2}{*}{$\begin{array}{l}\text { To support the solutions-oriented organisation, TSS had implemented a } \\
\text { business area-wide ERP system from JD Edwards. The system was } \\
\text { fundamental to the business model, enabling full visibility of available } \\
\text { components, providing input to and information from the logistics }\end{array}$} \\
\hline Price $(€)$ & $10 \mathrm{M}$ & & \\
\hline
\end{tabular}




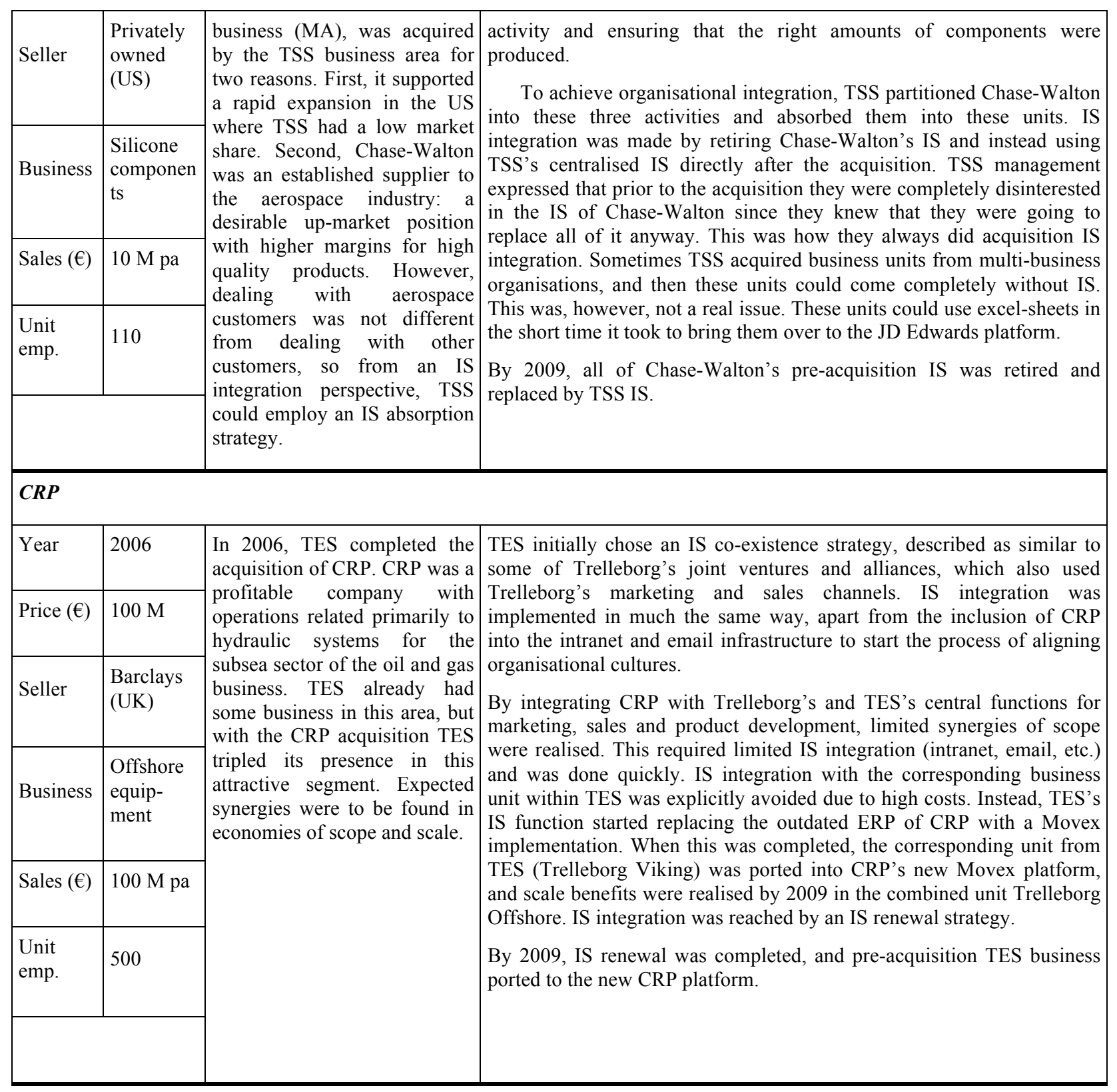


Table 5. Displayed routine-based and expertise knowledge

\begin{tabular}{|c|c|c|}
\hline Acquisition & Routine-based knowledge & Expertise knowledge \\
\hline Kléber & $\begin{array}{l}\text { Initially wrongly applied IS } \\
\text { absorption routine. No routine for } \\
\text { subsequent IS co-existence or IS } \\
\text { absorption strategies. }\end{array}$ & - NA \\
\hline Dynaflex & $\begin{array}{l}\text { Parts of routines developed for } \\
\text { intra-organisational IS integration } \\
\text { used for integration by IS co- } \\
\text { existence. }\end{array}$ & $\begin{array}{l}\text { - View of routines as set of modules that can be combined and } \\
\text { re-used in other routines. } \\
\text { - Understanding of how the IS absorption strategy affected the } \\
\text { target and benefits sought. } \\
\text { - Modification of existing IS integration routines to specific } \\
\text { challenges. }\end{array}$ \\
\hline $\begin{array}{l}\text { Chase- } \\
\text { Walton }\end{array}$ & $\begin{array}{l}\text { Highly efficient IS absorption } \\
\text { routine. }\end{array}$ & $\begin{array}{l}\text { - Understanding of routines beyond the specific acquisition at } \\
\text { hand. } \\
\text { - Assessment of what the organisation's IS integration routines } \\
\text { can and cannot be used for. }\end{array}$ \\
\hline CRP & $\begin{array}{l}\text { First, a routine for IS co-existence. } \\
\text { Then, no routine for IS renewal. }\end{array}$ & $\begin{array}{l}\text { - Correct generalisation of IS integration strategies and their } \\
\text { effects. } \\
\text { - Anticipations of problems associated with IS integration } \\
\text { strategies. } \\
\text { - Contextualisation of how financial position influenced the use } \\
\text { of routines. } \\
\text { - Combination of IS integration strategies. } \\
\text { - Broad approach with several potential continuations. }\end{array}$ \\
\hline
\end{tabular}


Table 6. Acquisition IS integration expertise categories and abilities

\begin{tabular}{|c|c|c|}
\hline $\begin{array}{l}\text { Expertise } \\
\text { abilities }\end{array}$ & Description & Exemplification and empirical support \\
\hline \multicolumn{3}{|l|}{ Categorisation } \\
\hline $\begin{array}{l}\text { Routine } \\
\text { categorisation }\end{array}$ & $\begin{array}{l}\text { Correct generalisations of } \\
\text { IS integration routines } \\
\text { and their effects. }\end{array}$ & $\begin{array}{l}\text { CRP: TES distinguished between the different routines employed for } \\
\text { different types of acquisitions and saw the similarities with the Kléber } \\
\text { case. } \\
\text { 'All acquisitions have their unique characteristics, but some things we } \\
\text { learnt... like that you cannot put a big company into the ERP of a } \\
\text { small company' (TES CIO). }\end{array}$ \\
\hline $\begin{array}{l}\text { Module } \\
\text { categorisation }\end{array}$ & $\begin{array}{l}\text { Higher granularity in the } \\
\text { view of IS integration } \\
\text { routines, regarding them } \\
\text { as sets of modules that } \\
\text { can be combined and } \\
\text { reused in routines. }\end{array}$ & $\begin{array}{l}\text { Dynaflex: Instead of applying the full routine, the IS integration group } \\
\text { regarded the routine as consisting of different modules that could be } \\
\text { combined with modules from other routines. } \\
\text { 'We used existing processes that we had created for previous projects. } \\
\text { I think that we only created one or two new processes' (TIH System } \\
\text { integrator). }\end{array}$ \\
\hline $\begin{array}{l}\text { Program } \\
\text { categorisation }\end{array}$ & $\begin{array}{l}\text { The role of routines } \\
\text { beyond the individual } \\
\text { acquisition in acquisition } \\
\text { programs. }\end{array}$ & $\begin{array}{l}\text { Chase-Walton: Acquisitions IS integration at TSS were not regarded } \\
\text { as isolated events, but as part of acquisition programs. } \\
\text { 'How we do IT integration fits with how we want to be growing. We } \\
\text { want to grow with our model. To do so we must bring the over to our } \\
\text { systems. Within a month they will be running on our systems' (TSS IT } \\
\text { specialist M\&A unit). }\end{array}$ \\
\hline \multicolumn{3}{|l|}{ Contextualisation } \\
\hline $\begin{array}{l}\text { Organisational } \\
\text { contextualisation }\end{array}$ & $\begin{array}{l}\text { How organisational } \\
\text { characteristics such as } \\
\text { financial position, } \\
\text { ownership, culture, etc. } \\
\text { influence the use of } \\
\text { routines. }\end{array}$ & $\begin{array}{l}\text { CRP: Trelleborg understood that its strong financial position at the } \\
\text { time of the acquisition facilitated integration stamina. } \\
\text { 'CRP were doing well when we bought them. And so did Trelleborg. } \\
\text { There was immediate urge to rush to action. We wanted them to feel } \\
\text { part of Trelleborg from day one, but the synergistic effects in } \\
\text { production and so on... they could wait until we knew the company } \\
\text { better and knew what we needed to do' (TESCFO). }\end{array}$ \\
\hline $\begin{array}{l}\text { Routine } \\
\text { implications }\end{array}$ & $\begin{array}{l}\text { How a specific IS } \\
\text { integration strategy } \\
\text { affects the target and } \\
\text { benefits sought. }\end{array}$ & $\begin{array}{l}\text { Dynaflex: The acquisition IS integration team understood how the } \\
\text { standard routine would lower Dynaflex's agility and flexibility. } \\
\text { 'The TIH sales department also did not want to implement a complex } \\
\text { standard package. Dynaflex was a small, efficient and flexible } \\
\text { business. If we had implemented the full Movex package, we would } \\
\text { have destroyed that flexibility' (TIH Operations Manager). }\end{array}$ \\
\hline $\begin{array}{l}\text { Problem } \\
\text { anticipation }\end{array}$ & $\begin{array}{l}\text { Risk associated with } \\
\text { given IS strategies. }\end{array}$ & $\begin{array}{l}\text { CRP: Comparing the CRP integration with the Kléber case, TES } \\
\text { decided that full consolidation of IS might have to wait until the next } \\
\text { major platform update. } \\
\text { 'CRP had been owned by a holding company for a long time. I knew } \\
\text { that these companies as a rule are underinvested to maximize profit in } \\
\text { the short time. When I heard about the acquisition I thought we better } \\
\text { look at how they are doing now, before announcing time plans' (TES } \\
\text { CIO). }\end{array}$ \\
\hline $\begin{array}{l}\text { Routine } \\
\text { applicability }\end{array}$ & $\begin{array}{l}\text { What the organisations IS } \\
\text { integration routines can }\end{array}$ & $\begin{array}{l}\text { Chase-Walton: TSS explained which acquisitions they could do, and } \\
\text { which were not possible to integrate with the existing routine. }\end{array}$ \\
\hline
\end{tabular}




\begin{tabular}{|l|l|l|l|}
\hline & and cannot be used for. & $\begin{array}{l}\text { 'If we were another company we would have integrated them } \\
\text { differently, but for us it is essential to have them into our model. } \\
\text { That's the kind of acquisition we can and should do' (TSS CFO). }\end{array}$ \\
\hline Customisation & $\begin{array}{l}\text { Modifying existing IS } \\
\text { integration routines to } \\
\text { specific challenges. }\end{array}$ & $\begin{array}{l}\text { Dynaflex: TES used an existing routine for Dynaflex, but made } \\
\text { modifications to keep the production IS instead of complete } \\
\text { absorption. } \\
\text { 'We knew that we needed to do something. But what was the best IT } \\
\text { solution? Should we install a system only for them, should we not } \\
\text { install any system at all... or should we integrate them into our } \\
\text { existing platform. .. We used what we had already. The difference } \\
\text { was that we deviated from the standard procedure in keeping the } \\
\text { production systems' (TIH Systems Integrator). }\end{array}$ \\
\hline Combination & $\begin{array}{l}\text { Combining IS integration } \\
\text { strategies, such as } \\
\text { temporal co-existence } \\
\text { and then renewal. }\end{array}$ & $\begin{array}{l}\text { CRP: When integrating CRP, TES decided to do a temporal co- } \\
\text { existence strategy, and then without time pressure rebuild the } \\
\text { complete IS base in a renewal strategy. } \\
\text { 'We gave them a new ERP. The one they had really constrained } \\
\text { business and gave them problems. So we made a Movex } \\
\text { implementation that also was integrated with our central functions. } \\
\text { After that we could move matching business onto that platform and } \\
\text { realize also synergies that we avoided initially' (TES CFO). }\end{array}$ \\
\hline Improvisation & $\begin{array}{l}\text { Outlining scenarios and } \\
\text { make detailed decisions } \\
\text { as the conditions become } \\
\text { clear. }\end{array}$ & $\begin{array}{l}\text { CRP: Understanding of potential problems and ways to address them } \\
\text { made possible an initial broad approach and subsequent improvisation } \\
\text { when integrating CRP. } \\
\text { 'We had to be open for possibilities since we didn't exactly know what } \\
\text { they had. And we didn't really know what we wanted neither. So we } \\
\text { kept the door open for several options' (TES CFO). }\end{array}$ \\
\hline
\end{tabular}

